\title{
A Study to Analyse the Content of Agricultural Extension Magazine about Rural Women Development Subjects during the Period from 1/1/2012 to 31/12/2016.
}

Ahmed M. A. ${ }^{1}$; A. M. El- Gohary ${ }^{1}$; E. F. El-Zahar ${ }^{2}$ and Maha M. M. Fera ${ }^{1}$ ${ }^{1}$ Tanta University - Faculty of Agriculture - Agricultural Economics Department.

${ }^{2}$ Agricultural Extension and Rural Development Research.

\section{دراسة لتحليل مضمون مجلة الإرشاد الزراعي في الموضوعات المتعلقة بتمية المرأة الريفية خلال الفترة من

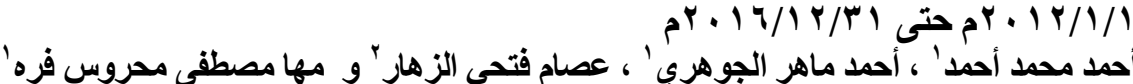

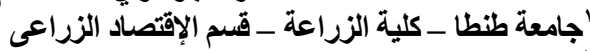 'مركز بحوث الإرشاد الزراعى والتنمية الريفية}

\begin{abstract}
الملخص

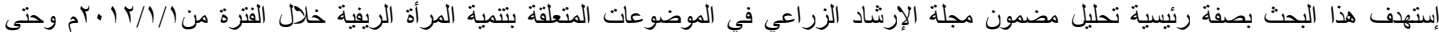

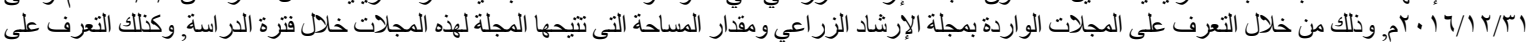

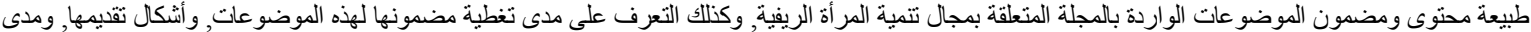

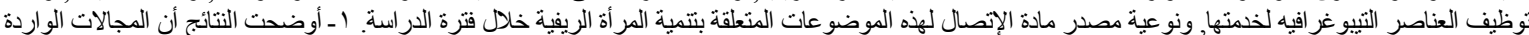

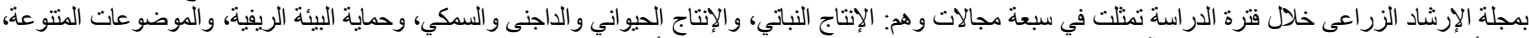

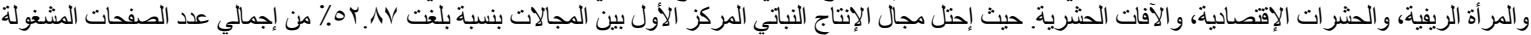

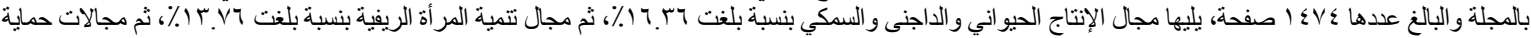

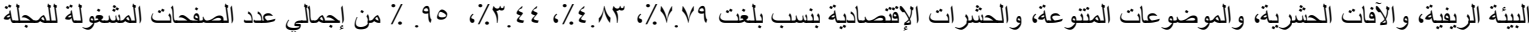

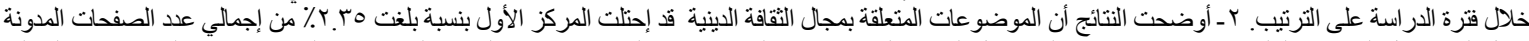

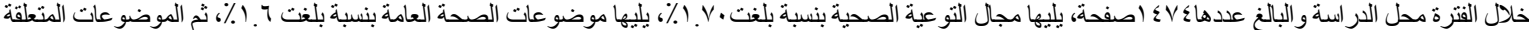

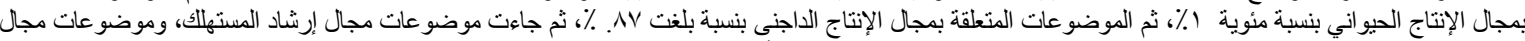

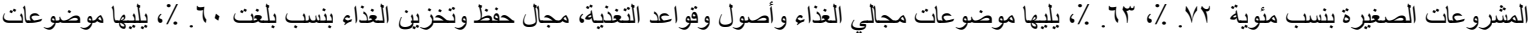

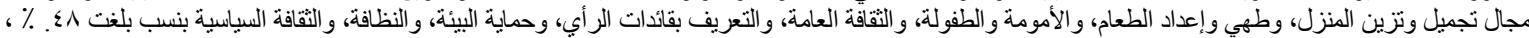

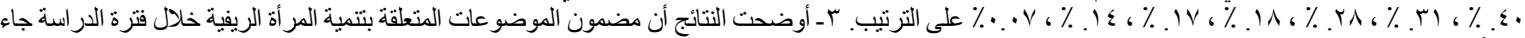

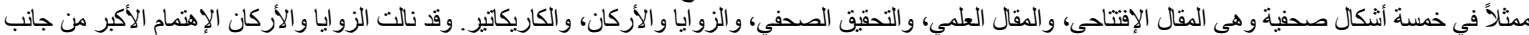

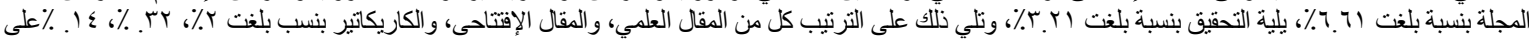

و الأفكار المستحدثة في مختلف المجالات من مصادر ها البحثية إلى المستهدفين

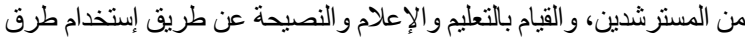

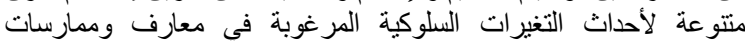

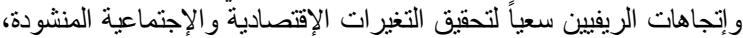
(Swanson,1990, p:37)

ويسعى الإرشاد الزراعي إلى تطوير آليات عمله من خلال تطوير

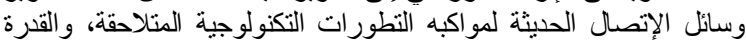

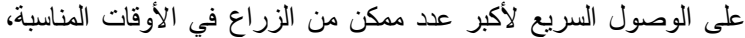

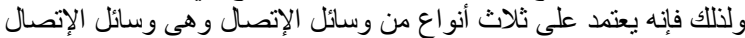

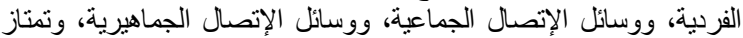

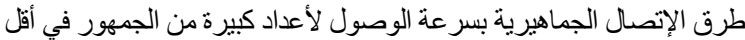

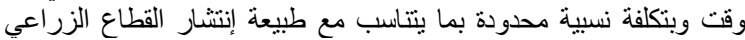
جغرافيا، وهذه الميزة تكون أكثر مناسبة في نشر الأفكار الجديدة وفى أوقات

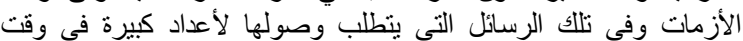

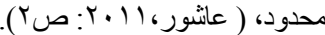

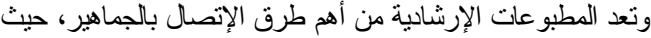

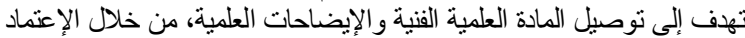

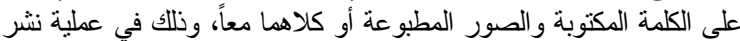

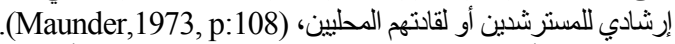

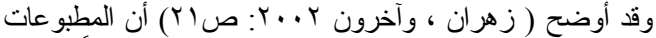

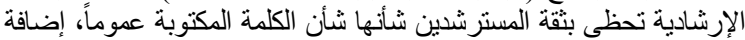

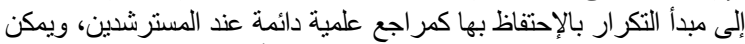

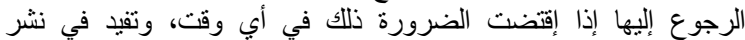

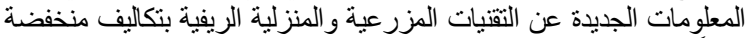

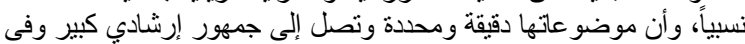
أقصر وقت، كما إنها تكمل وتدعم وتزيد من فاعلية الطرق الإرشادية الأخرى.

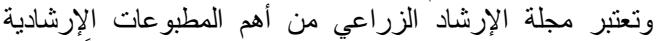

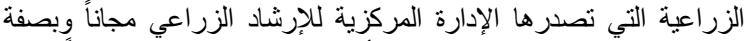

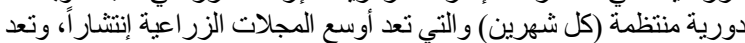

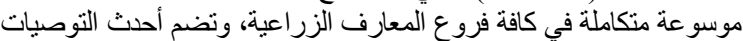

\section{المقدمة و المشكلة البحثية}

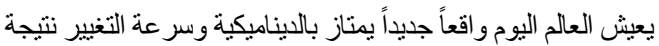

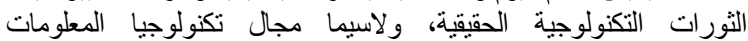

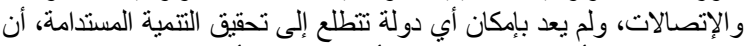

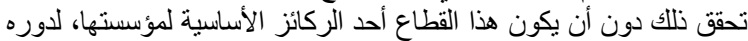

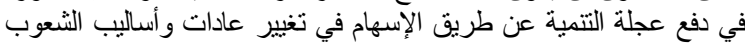

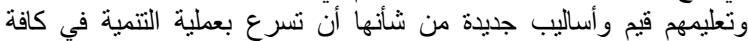

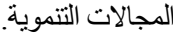

وتعتبر وسائل الإتصال الجماهيرية أحد شروط التتمية لكونها أهم

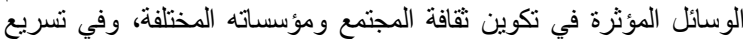

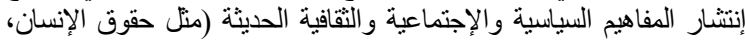

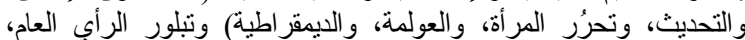

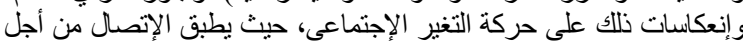

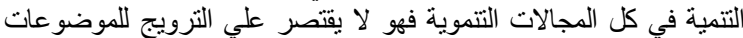
الزراعية فقط ولكناه يستخدم في برامج التخذية والتية والصحة الإنجابية والإنتاج

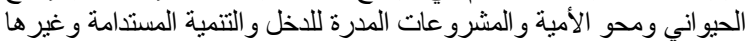

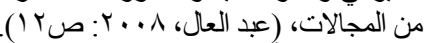

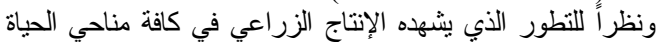

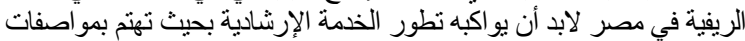

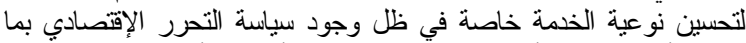

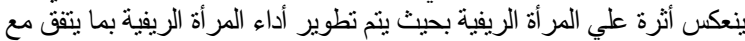

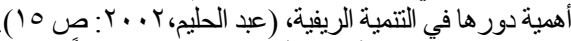

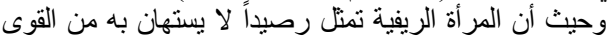

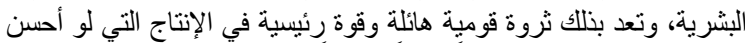

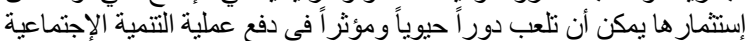

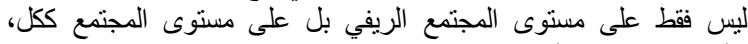

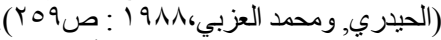
ويعتبر الإرشاد الزر اعي أحد المكونات الأساسية في برامج التمبية

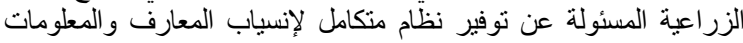


عـ ـ دراسة أثنكال تقديم الموضوعات التى تخدم مجال تتمية المرأة الريفية

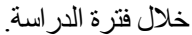

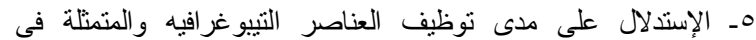

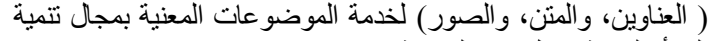

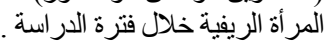

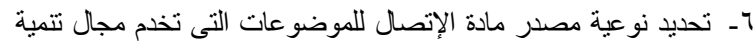
المر أة الريفية خلال فترة الدراسة.

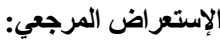

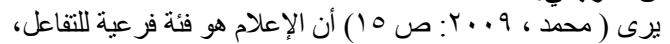

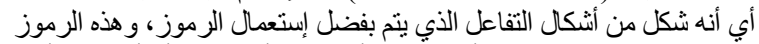

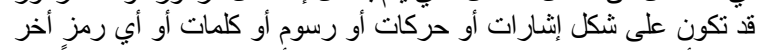

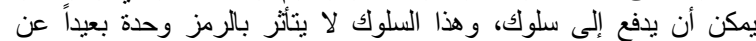
الظروف المحيطة بالثخص المسلى المستجيب أو المنلقي.

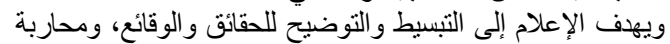

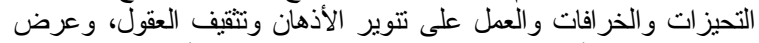

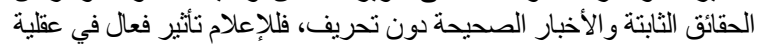

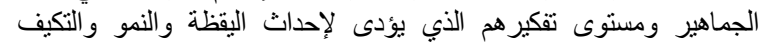

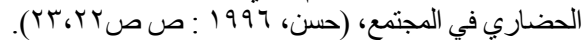

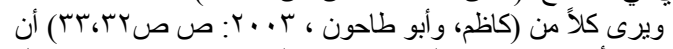

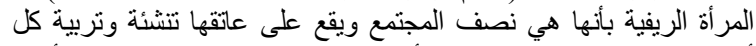

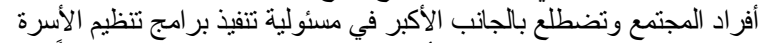

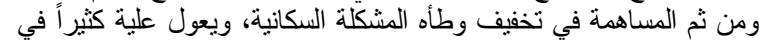

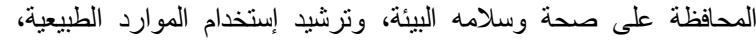

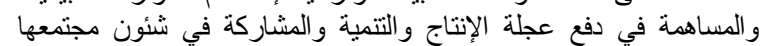
المحلى وحل مثناكله، و إذا ما توفر لها أسباب إطلاق طاقتهاً الكامنة وتوظيفها في عمليات التتمية.

حيث تتعدد وتتفرع مجالات عمل الإرشاد الزراعي لتحقيق التنمية

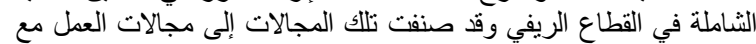

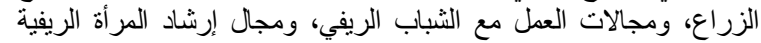

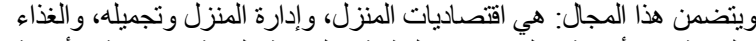

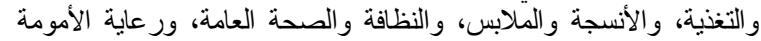

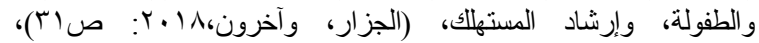

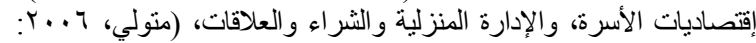

وتعد الصحافة المطبو عة أحد طرف الإتصال الإرشادي التي بمكن

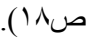

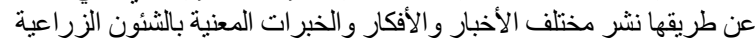

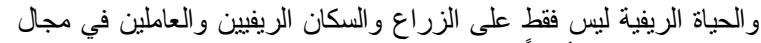

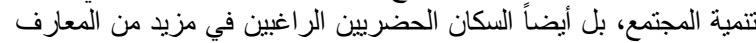

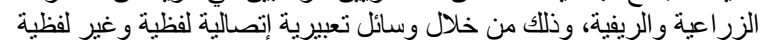

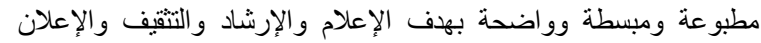

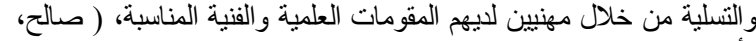

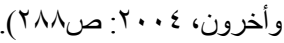

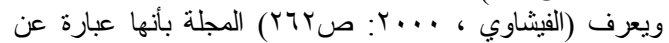

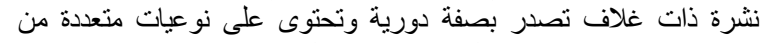

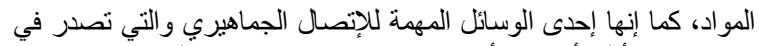

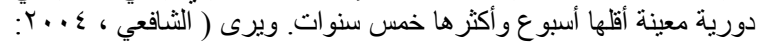

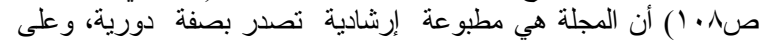

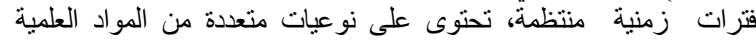

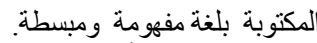

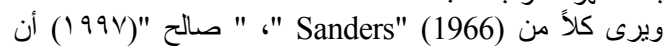

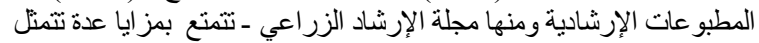

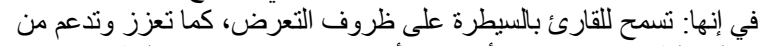

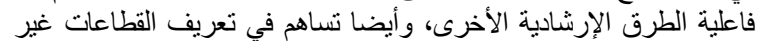

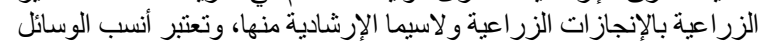

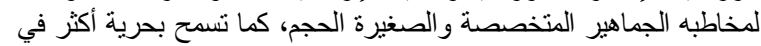

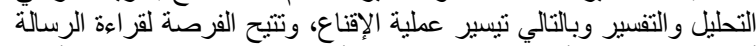

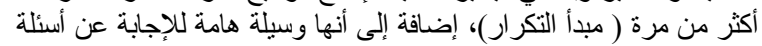

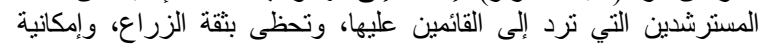
الإحتفاظ بها كمر اجع علمية.

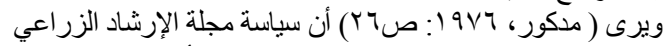
تسنهدف تطوير المجتمع الريفي وير اعى عند إعدادها عدة أسس منها: معالجة الزّة
الفنية المستحثثة في مختلف المجالات الزراعية وشئون الحياة الريفية

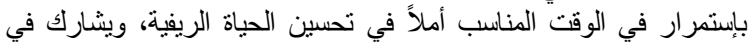

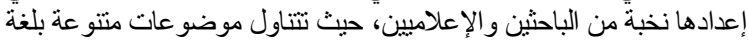

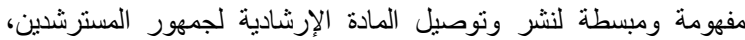

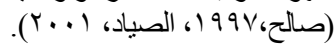

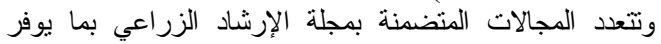

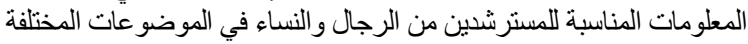

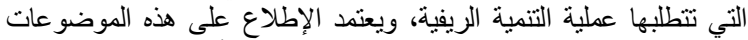

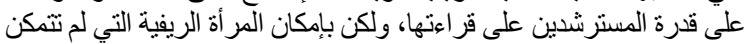

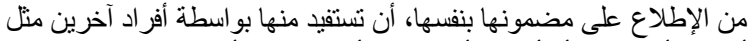

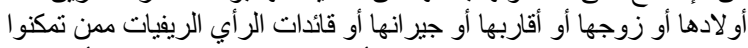

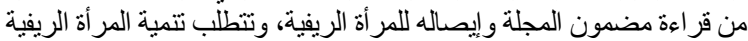

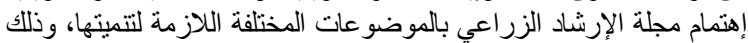

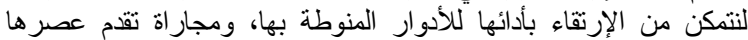

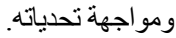

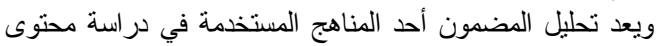

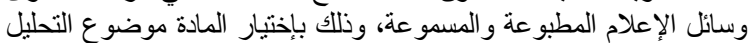

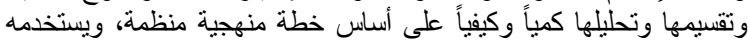

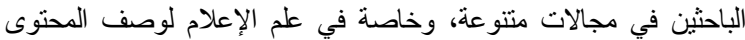

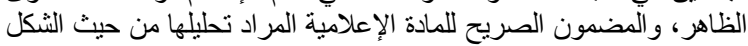

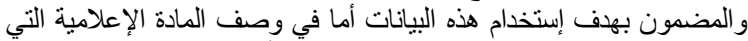

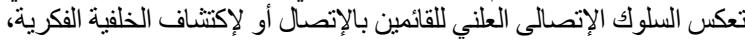

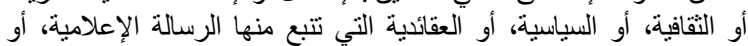

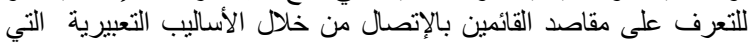

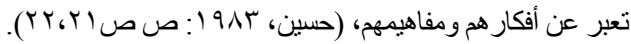

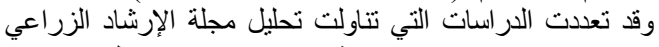

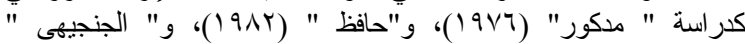

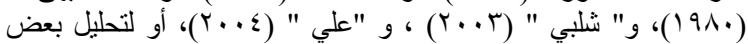

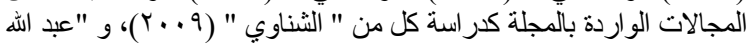

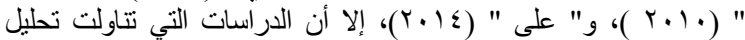

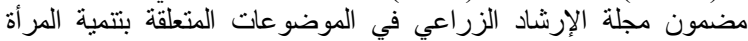

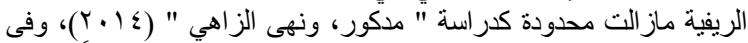

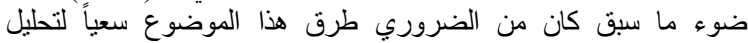

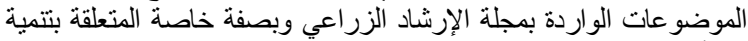

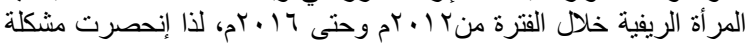

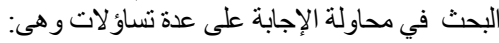

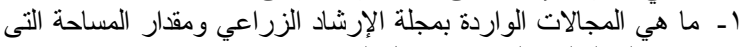

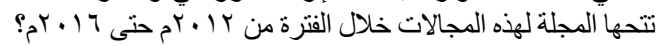

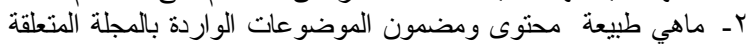

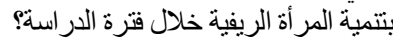

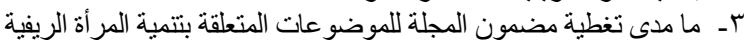

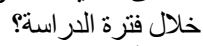

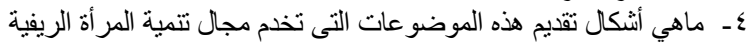

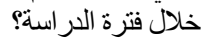

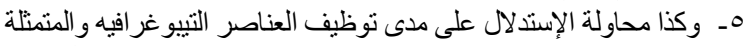

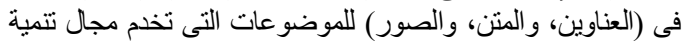

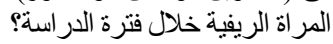

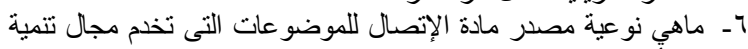

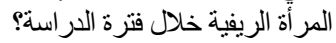

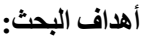

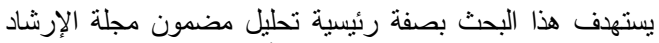

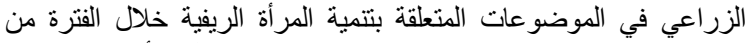

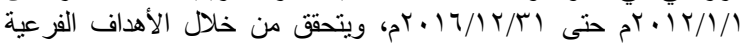

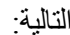

1 - التعرف على المجالات الواردة بالمجلة ومقدار المساحة التى تتحها المجلة

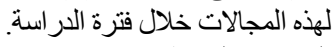

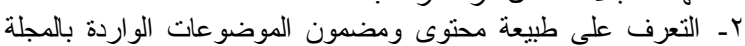

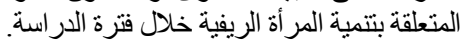

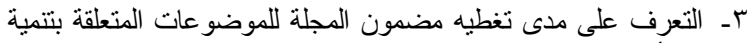

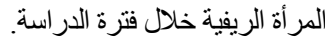


علي الجو انب الموضو عية فقط و إنما يشمل الجوانب الثكلية أيضاً. ـ ـ ترتبط

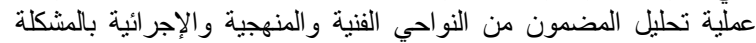

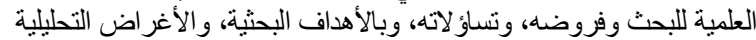

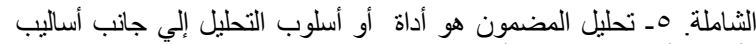

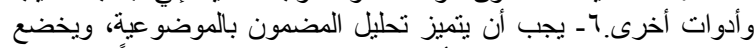

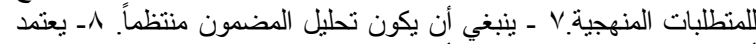

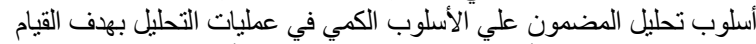

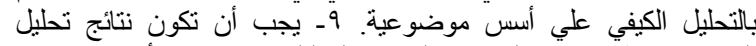

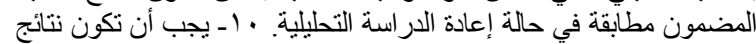
تحليل المضمون قابلة للتعميم.

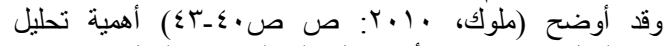

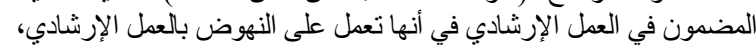

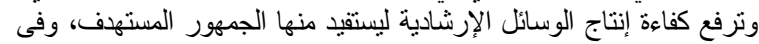

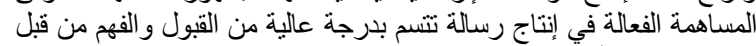

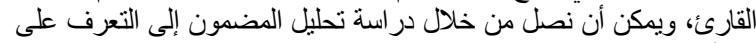

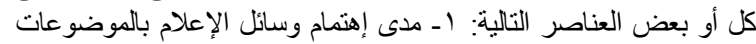

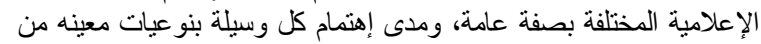

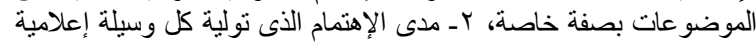

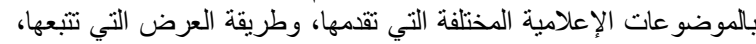

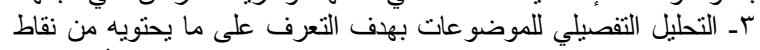

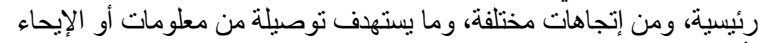

\section{الطريقة البحثية}

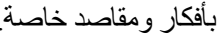

أولاً: شاملة وعينة مادة التحليل:

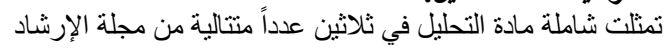

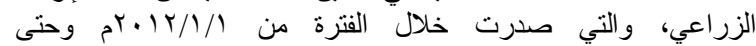

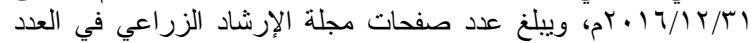

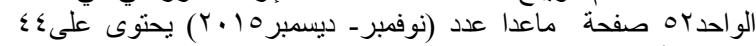

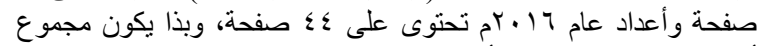

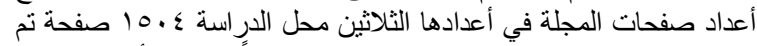

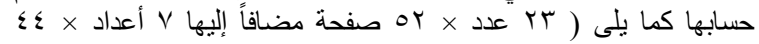

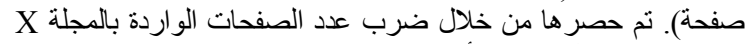

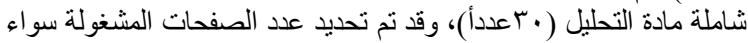

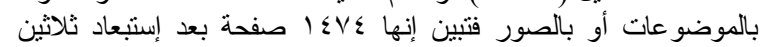

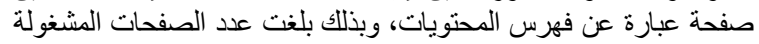

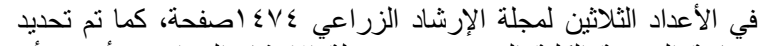

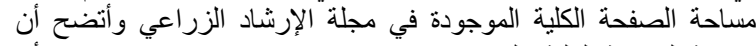

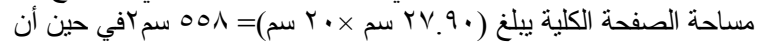

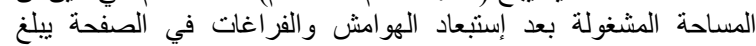

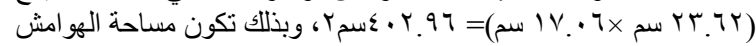

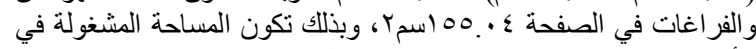

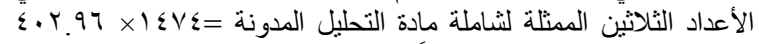

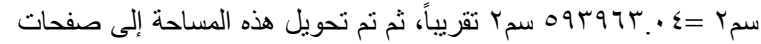

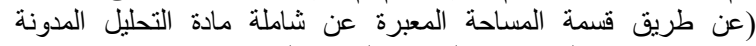

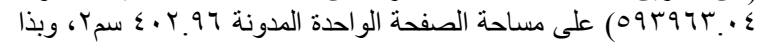

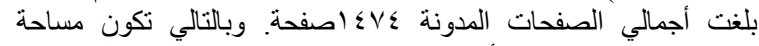

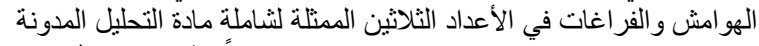

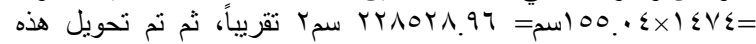

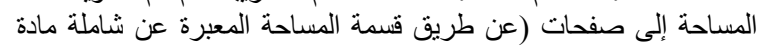

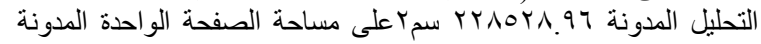

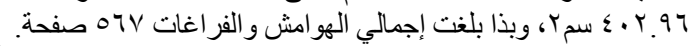

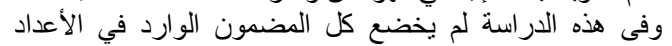

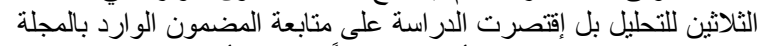

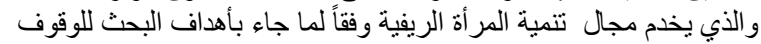

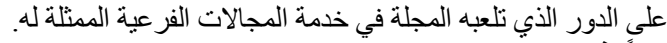
ثانياً: فئات تحليل المضمون: الفئ

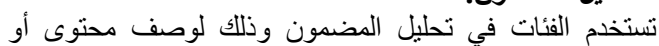

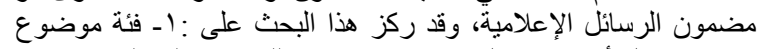

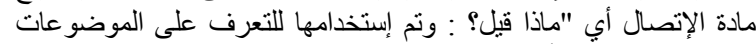

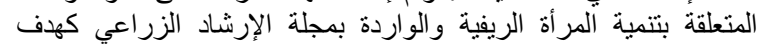

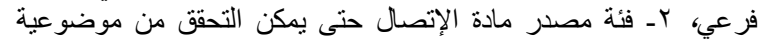

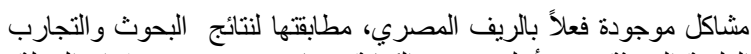

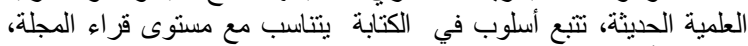

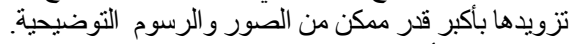

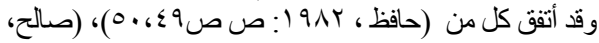

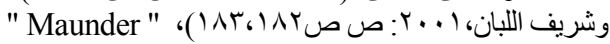

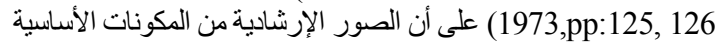

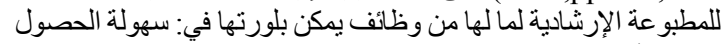

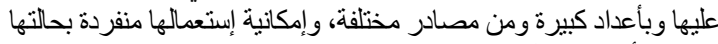

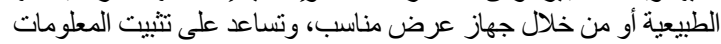

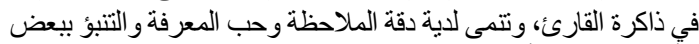

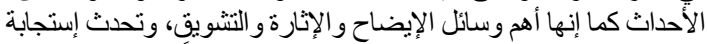

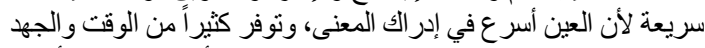

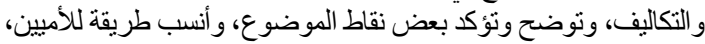

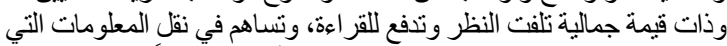

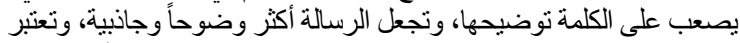

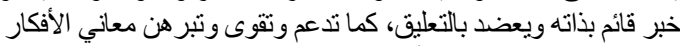

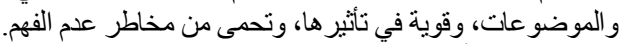

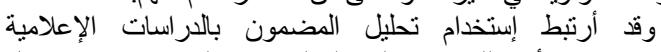

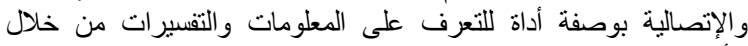

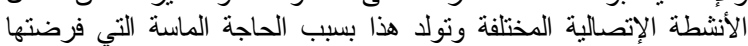

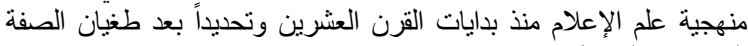

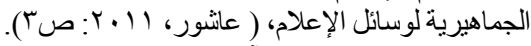

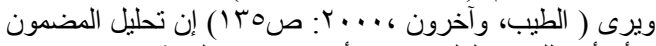

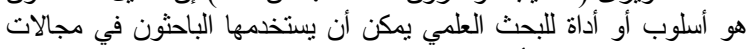
بحثية متتوعة و علي الأخص في علم الإعلام، حيث تصف الإن المحتوى الظاهر

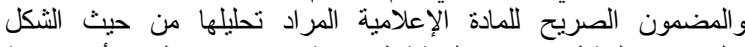

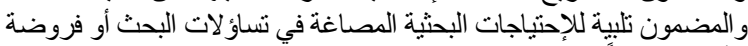

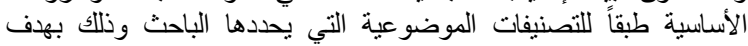

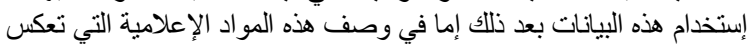

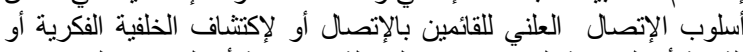

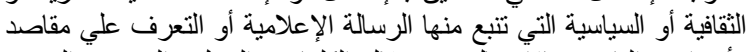

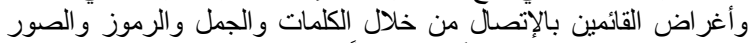

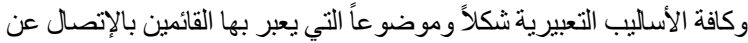

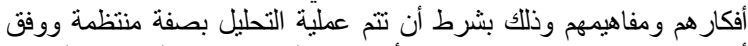

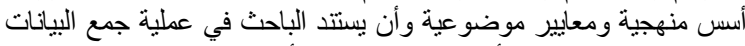

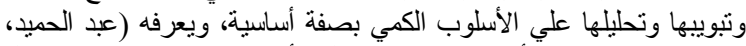

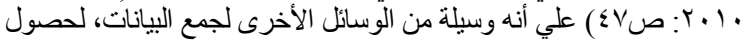

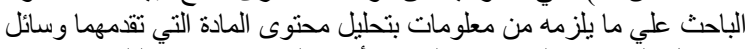

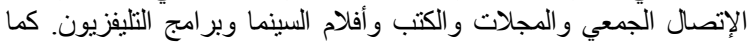

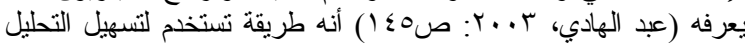

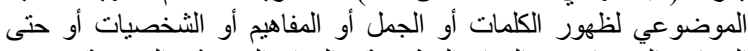

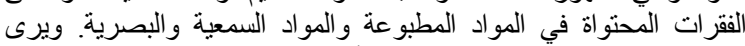

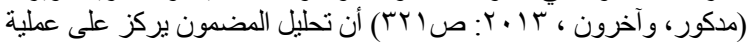

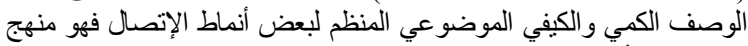

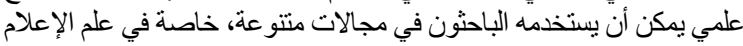

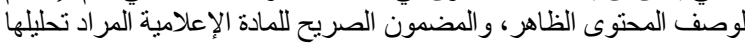
من حيث الثكل و المضمون.

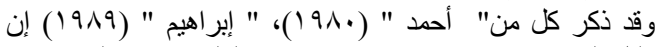

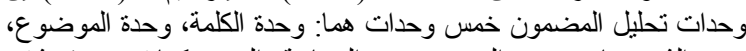

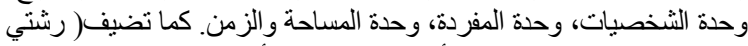

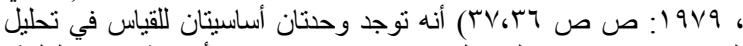

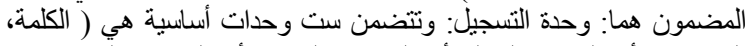

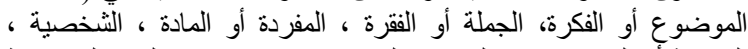

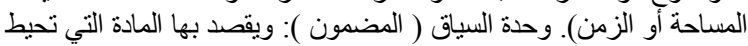

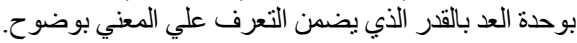

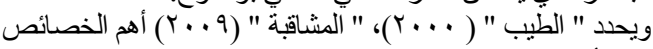

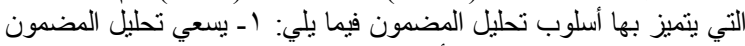

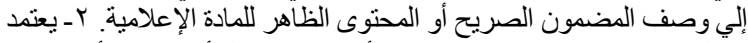

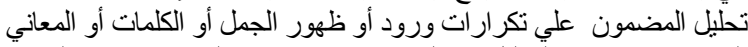

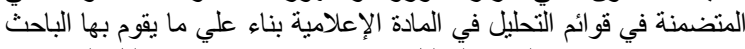

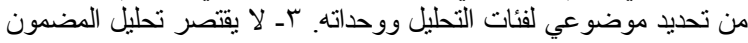




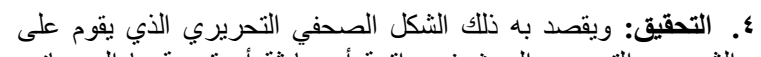

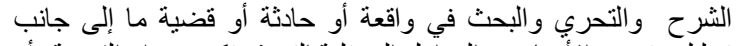

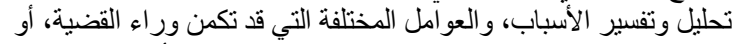

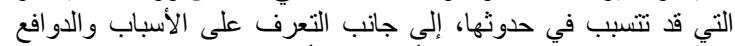

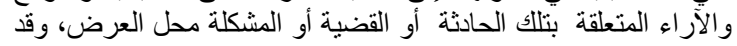

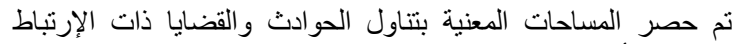
بتنمية المر أة الريفية.

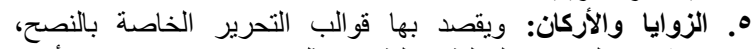

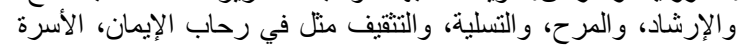

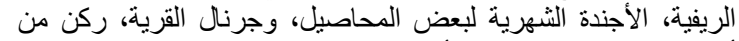

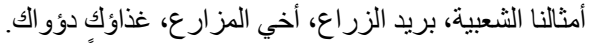

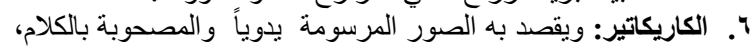

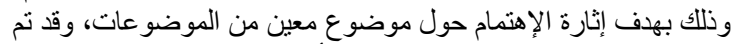

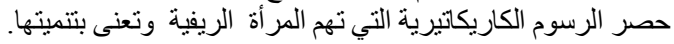

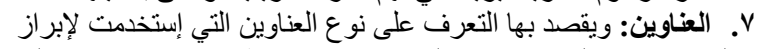

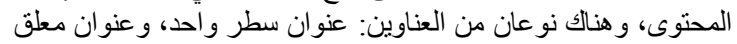

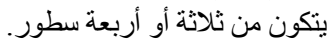

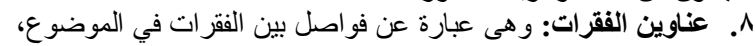

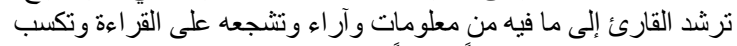

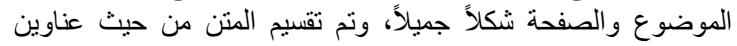

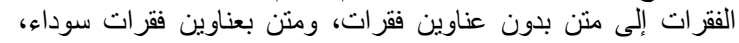

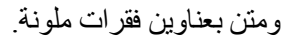
9. الأرضيات: ويقصد بهارئ وضلنع أرضية رمادية أو غيرها من أثكال

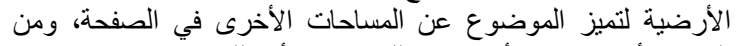

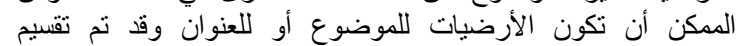
الأرضيات إلى ملونة ورمادية.

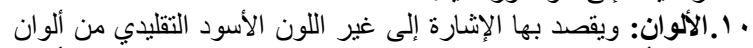

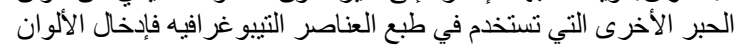

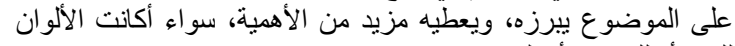

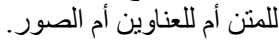

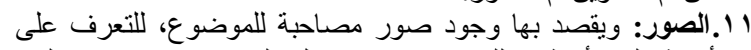

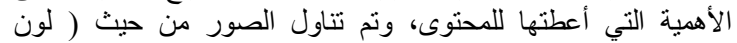

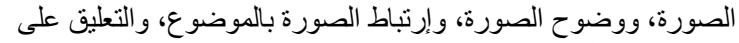

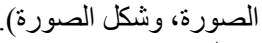

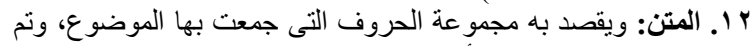

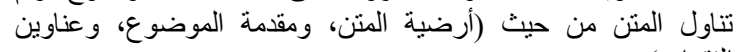

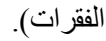

\section{الانتائج}

أولاً: المجلات الواردة بمجلة الإرشاد الزراعي ومقدار المساحة التى تتحها

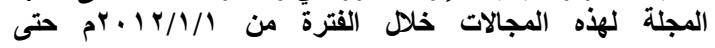

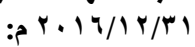

للوقوف علي طبيعة ونو منية المجلات التي تناولتها مجلة الإرشاد

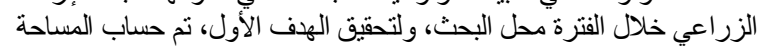

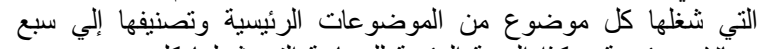

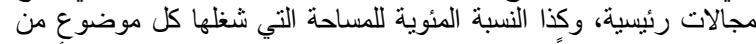

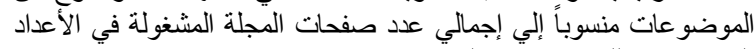
التي خضعت للبحث في هذه الدرأسة.

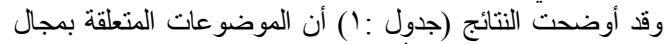

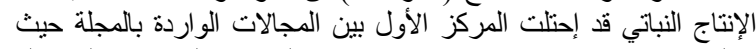

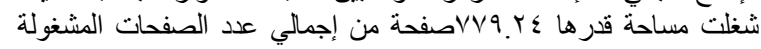

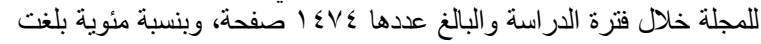
و or.AV

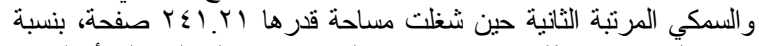

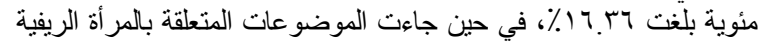

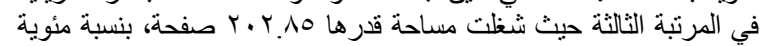

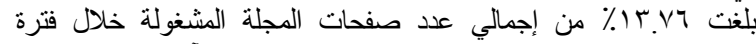

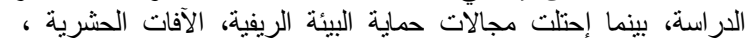

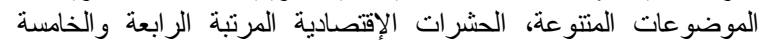

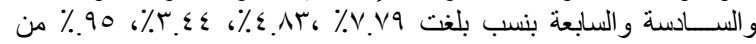

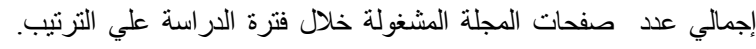

مصدر مادة الإتصال ويقصد بها مصدر المضمون أو المواد المحررة

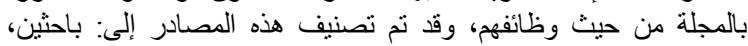

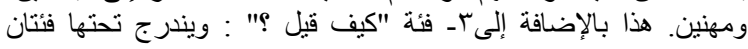
فر عيتان هما:

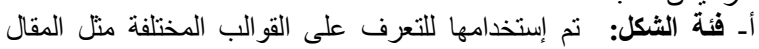

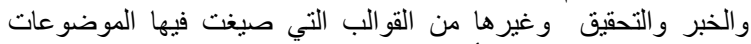
المختلفة المتعلقة بتتمية المر أة الريفية الو اردة بمجلة الإرشاد الزئر اعي كهدف

فرعى. بـ فئة العناصر التيبوغرافيه: وهى (العناوين، المتن، الصورة، الألوان،

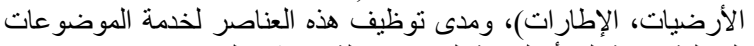

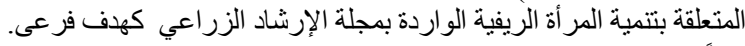
ثالثاً: وحدات تحليل المضمون: بستهدف أسلوب القفياس في منهج تحليل المضمون تحويل

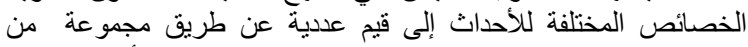

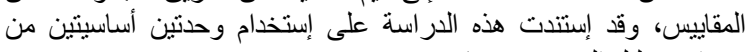

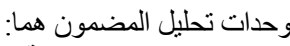

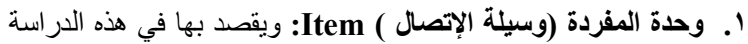

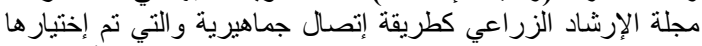

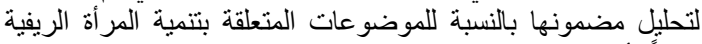
نظر أ لأهميتها البحثية.

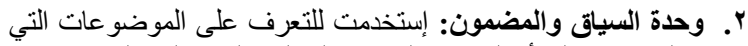

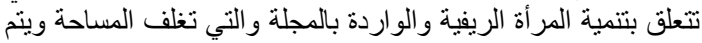

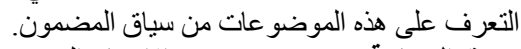

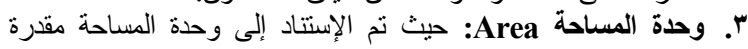

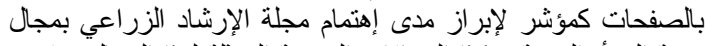

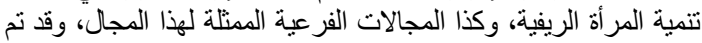

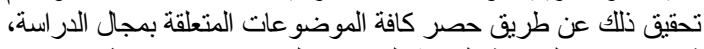

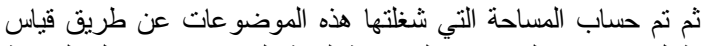

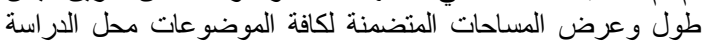

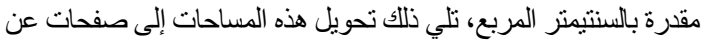

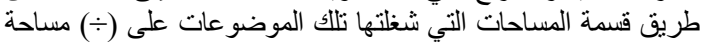

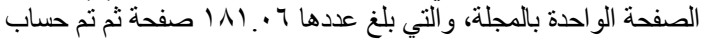

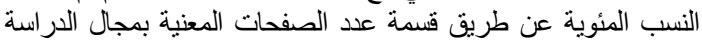

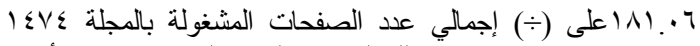

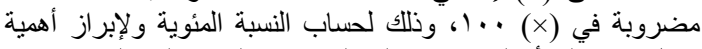

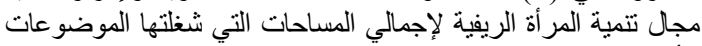

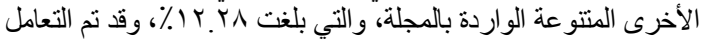

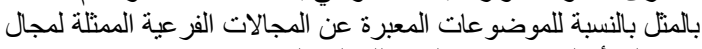

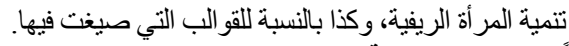

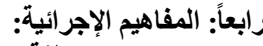

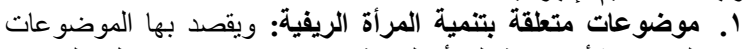

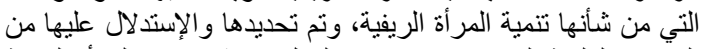

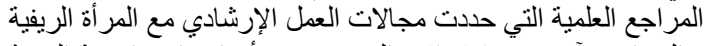

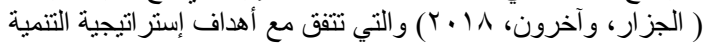

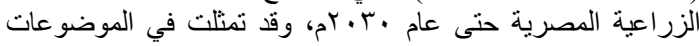

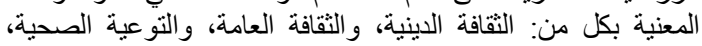

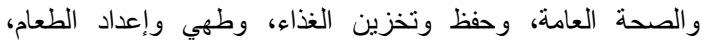

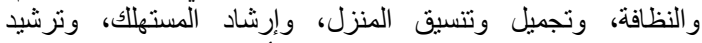

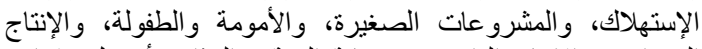

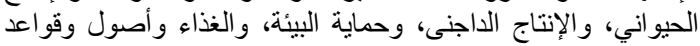

r. المقال الإفتتاحى: وهو نوع من الكتابات الصحفية التي ت تأخذ شكلاً

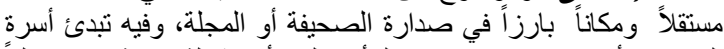

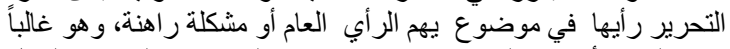

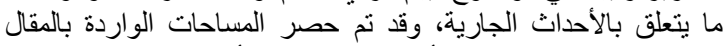

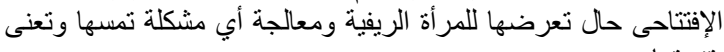

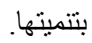

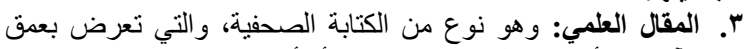

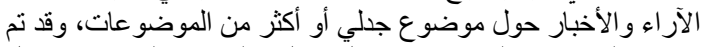

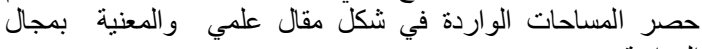
الار اسة. - مان. 
جدول ا. توزيع إجمالي عدد الصفحات والنسب المئوية للمجالات الواردة بمجلة الإرشاد الزراعي خلا فترة الاراسة من // / I ـrم حتى

\begin{tabular}{|c|c|c|c|c|c|c|c|c|}
\hline \multirow{4}{*}{ الترتيب } & \multirow{4}{*}{$* \%$} & \multirow{4}{*}{ الإجمالي } & \multirow{2}{*}{\multicolumn{5}{|c|}{ علد الصفحات خلال الأعوام }} & \multirow{3}{*}{ المجالات } \\
\hline & & & & & & & & \\
\hline & & & \multirow{2}{*}{ 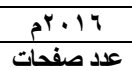 } & \multirow{2}{*}{ علد صفحات } & \multirow{2}{*}{ علد صفحات } & \multirow{2}{*}{ عدد صفحات } & \multirow{2}{*}{ 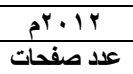 } & \\
\hline & & & & & & & & \\
\hline$T$ & Or.AY & WVq.Y & $1 \leq 7.11$ & 177.9 & $17 \leqslant .10$ & 104.94 & $1 \leqslant 1.9 r$ & الإنتاج النباتي \\
\hline r & 17.47 & $r \leq 1, r)$ & 49.01 & ov.11 & $\varepsilon r . v r$ & $\leqslant 9.9$ & $01 . V V$ & الإنتاج \\
\hline$\varepsilon$ & v. vq & $\| \leqslant . \wedge 1$ & KY.YA & $r \leqslant . r$ & $r \leq . \wedge T$ & $19 . \leqslant 9$ & $r \leqslant . r T$ & حمايةً \\
\hline 1 & $r . \leq \varepsilon$ & $0.1 \mathrm{V4}$ & 1.10 & $1.0 \leqslant$ & $11 . \cdot \leq$ & IV.KT & Ir.r & الموضو عات المتتو عة \\
\hline r & $15 . V 7$ & $r \cdot r . \wedge 0$ & rq. ro & ro.91 & $\leqslant 1 . \pi$ & $\leqslant 0.90$ & ד. 0. & المر أة الريفية \\
\hline v & .90 & $1 \leq . r$ & - & $\lambda \varepsilon$ & r.vi & $\varepsilon . V^{\prime}$ & $\varepsilon v$ & الحشرات الإقتصادية \\
\hline \multirow[t]{2}{*}{ 。 } & ¿.^r & vilv & 19.9 & $0 . \leqslant 1$ & IV.r. & $10.0 \leqslant$ & דג.זו & الآفات الحشرية \\
\hline & $1 \cdots$ & $1 \leqslant V \leqslant$ & rON & rqA & $r \cdot 1$ & $r \cdot 7$ & $r .7$ & الإجمالي \\
\hline
\end{tabular}

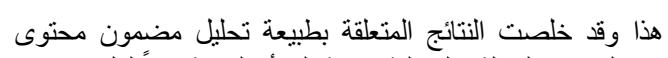

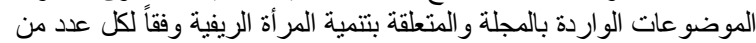

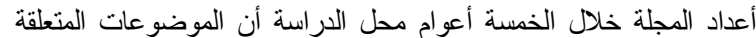

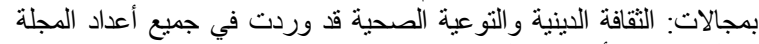

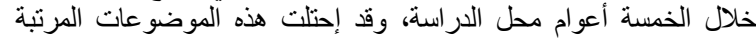

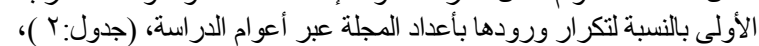

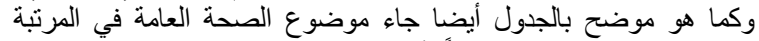

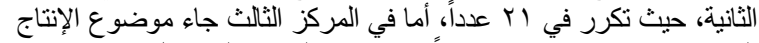

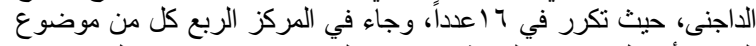

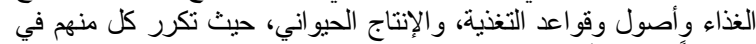

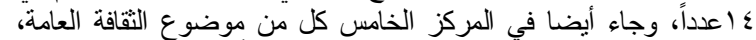

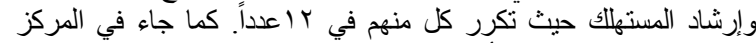

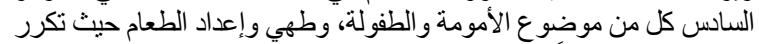

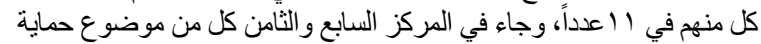

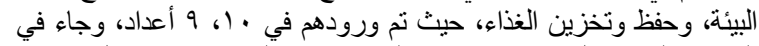

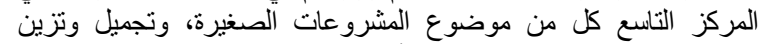

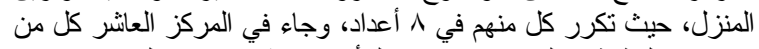

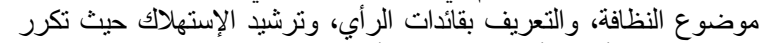

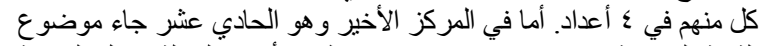

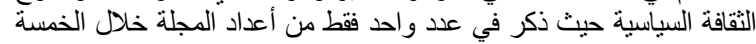

أعوام محل الدراسة.

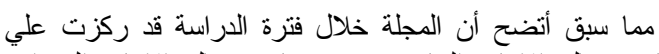

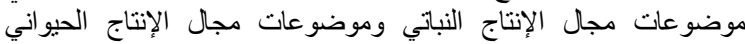

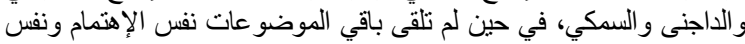

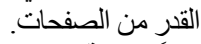
ثانياً: طبيعة محتوى ومضمون الموضئ الموضوعات الواردة بمجلة الإرشاد الزراعي

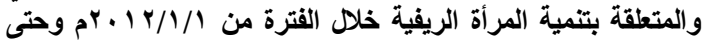

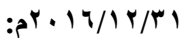

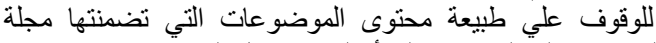

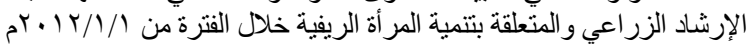

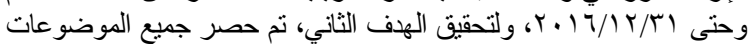

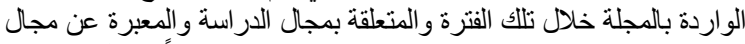

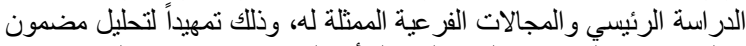

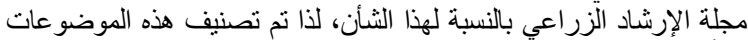

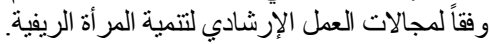

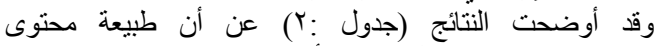

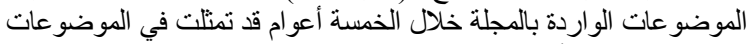

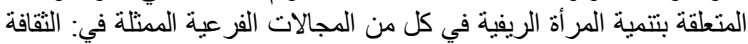

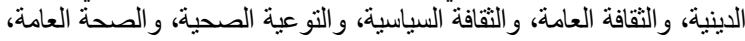

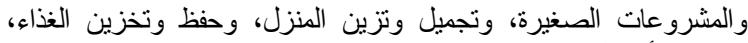

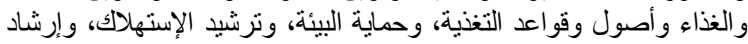

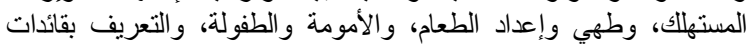
الر أي، والنظافة، والإنتاج الحيو اني، و الإنتاج الداجنى.

\begin{tabular}{|c|c|c|c|c|c|c|c|}
\hline الترتيب & الإجمالي & Pr.17 & $5 r+10$ & Pr. Is & pr.1r & $p^{r+1 r}$ & الموضوعات \\
\hline 1 & $r$. & 7 & 7 & 7 & 7 & 7 & الثقافة الدينية \\
\hline 11 & 1 & - & 1 & - & - & - & الثقافة السباسية \\
\hline 0 & ir & - & r & r & r & $\varepsilon$ & الثقافة العامة \\
\hline 1 & r. & 7 & 1 & 1 & 7 & 7 & التو عية الصحية \\
\hline r & ri & 1 & $\varepsilon$ & $\varepsilon$ & 7 & 7 & الصحة العامة \\
\hline 9 & $\wedge$ & - & $r$ & r & 1 & 1 & المشرو عات الصغيرة \\
\hline$\wedge$ & 9 & r & 1 & 1 & r & r & حفظ وتخزين الغذاء \\
\hline$\varepsilon$ & $1 \leqslant$ & r & r & $\varepsilon$ & r & $\varepsilon$ & الغذاء وأصول وقو اعد التغذية \\
\hline v & 1. & 1 & 1 & 1 & 。 & r & حماية البيئة \\
\hline 9 & $\wedge$ & 1 & 1 & r & 1 & r & تجميل وتزين المنزل \\
\hline 1. & $\varepsilon$ & - & - & - & r & r & ترشيد الإستهلاك \\
\hline o & Ir & 1 & r & $\varepsilon$ & r & r & إرشاد المستهلك \\
\hline 1 & 11 & - & r & r & r & 0 & الأمومة و الطفولة \\
\hline 7 & 11 & r & 1 & r & $\varepsilon$ & r & طهي وإعداد الطعام \\
\hline 1. & $\varepsilon$ & - & r & - & - & r & النظأفـــة \\
\hline 1. & $\varepsilon$ & r & 1 & - & 1 & - & التعريف بقائدات الر أي \\
\hline$\varepsilon$ & $1 \varepsilon$ & 1 & r & $\varepsilon$ & r & $\varepsilon$ & الإنتاج الحيو اني \\
\hline r & 17 & r & $\varepsilon$ & $\varepsilon$ & r & r & الإنتاج الداجنى" \\
\hline
\end{tabular}

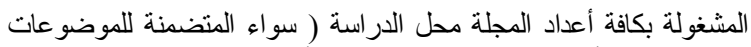

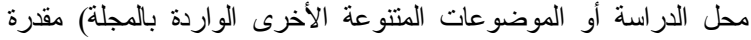

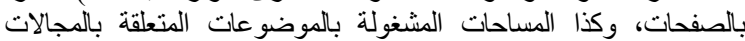

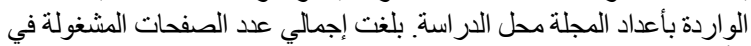

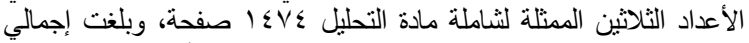

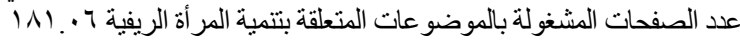

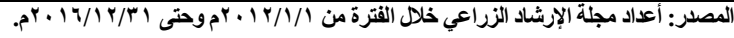

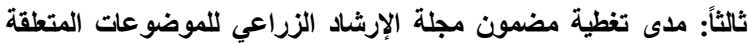

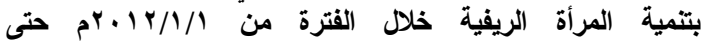

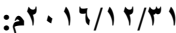

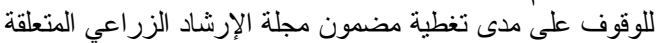

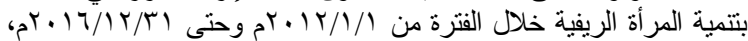
ولتحقيق الهدف البحثي الثالث، إستلزم الأمر الإستدلال على الثى المساحات 


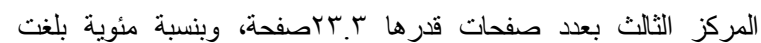

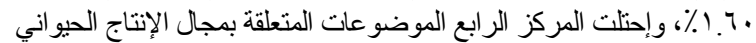

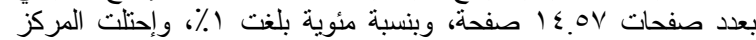

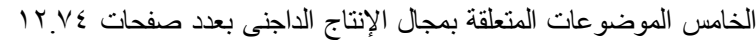

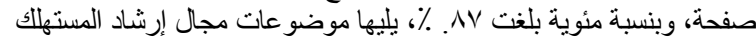

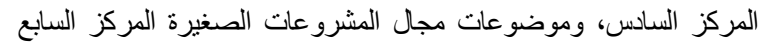

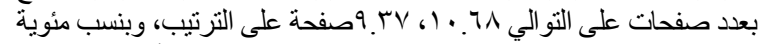

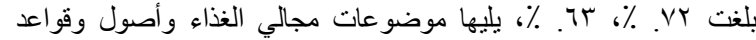

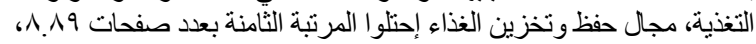

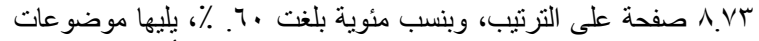

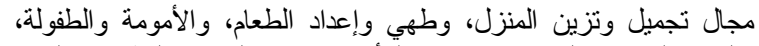

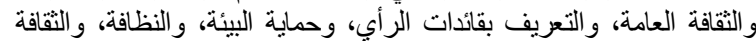

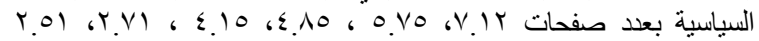

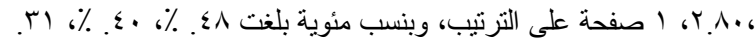

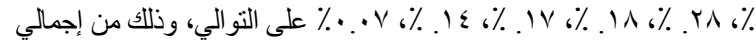

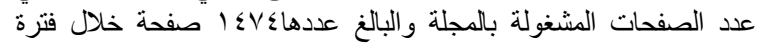

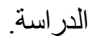

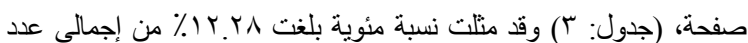

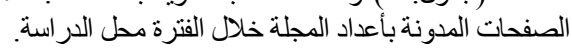

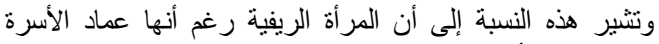

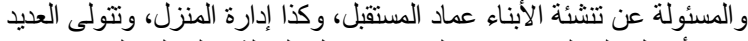

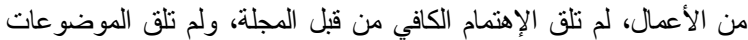

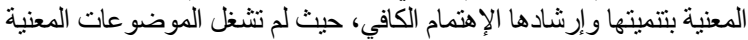

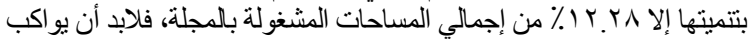

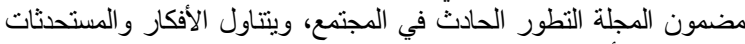

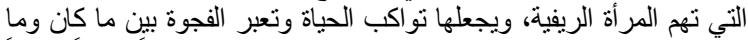
يجب أن بكون، فالمجلة الإرشادية تحمل رسالة إعلامية ودوراً تتموياً منوطاً

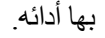

وقد أوضحت النتائج ( جدول :؟r) أن الموضوعات المتعلقة بمجال

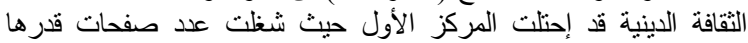

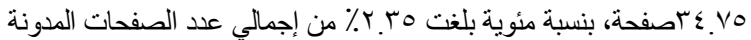

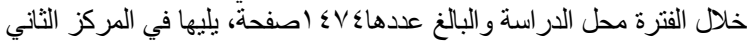

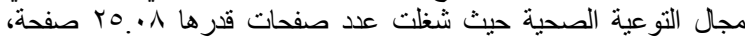

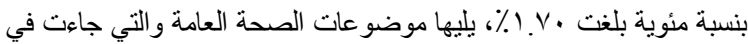

جدول r. أجمالي عدد الصفحات والنسب المئوية لكل من موضوعات مجلة الإرشاد الزراعي المتعلقة بتنمية المرأة الريفية خلال فترة الدراسة من

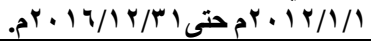

\begin{tabular}{|c|c|c|c|c|c|c|c|c|}
\hline \multicolumn{8}{|c|}{ عدد الصفحات خلال الأعوام } & \multirow{3}{*}{ ل لموضوعات } \\
\hline \multirow{2}{*}{ الترتيب } & \multirow{2}{*}{$* \%$} & \multirow{2}{*}{ الإجمالي } & Pr. 17 & $5^{Y+10}$ & $p^{r+1 \varepsilon}$ & pr. & Pr. Ir & \\
\hline & & & عدد صفحات & علد صفحات & عدد صفحات & عدد صفحات & عدد صفحات & \\
\hline 1 & r.ro & re.vo & 7 & $V .9$ & $7 . \wedge \wedge$ & $v .4$ & V.Vo & الثقافة الدينية \\
\hline it & rᄉ & $\leqslant 10$ & - & $\wedge$. & $1 . r 0$ & $1 . r 0$ & 10 & الثقافة العامة \\
\hline 10 & $\because v$ & 1 & - & 1 & - & - & - & الثقافة السياسية \\
\hline r & I.V. & ro. 1 & r.11 & r.vA & צ. & $7 . \leqslant 7$ & $V . \leqslant V$ & التوعية الصحية \\
\hline r & 1.7 & מ.T"ז & 1 & $\varepsilon .77$ & r.9V & 0.94 & V. vo & الصحة العامة \\
\hline$\wedge$ & .7 . & $\wedge . \wedge 9$ & $r .7$ & $1 . \leqslant r$ & Tr & 1.17 & 1.94 & الغذاء و أصول وقو اعد التغذية \\
\hline 1. & $\varepsilon$. & 0.10 & .09 & rᄉ & At & Y.TE & $1 . \leqslant r$ & طهي و أعداد الطعام \\
\hline$\wedge$ & .7. & A.VT & r.Ar & 1.1 & .17 & I. 1. & I. $\wedge V$ & حفظَّوتخزين الغذاء \\
\hline V & זדי. & $9 . \mathrm{rV}$ & - & r.9r & אד.T & .90 &.$\wedge V$ & المشروعات الصغيرة \\
\hline 11 & ו & $\leqslant .10$ & - & .70 & r人 & I.rT & T.T. & الأمومة والطفولة \\
\hline r & .11 & r.^. & - & or & - & - & t. rA & النظافة \\
\hline 9 &.$\leqslant \Lambda$ & V.IT & Tr & 1.11 & .90 & $1 . M$ & t.IT & تجميل وتزين المنزل \\
\hline 7 &.$V Y$ & $1 \cdot .71$ & r. & 1.11 & $r . v$ & ס 1.1 & $1 . v \varepsilon$ & إرشاد المستهلك \\
\hline 10 & $.1 \leqslant$ & $r .7$ & - & - & - & $1 . \leqslant 1$ & .70 & ترشيد الإستهلاك \\
\hline IT & .11 & Y.VI & 1.4 & .09 & - &.$\wedge 1$ & - & التعريف بقائدات الر أي \\
\hline $1 \leq$ & $.1 \mathrm{~V}$ & r.01 & - & . & (Y) & 1.09 & 0 . & حمايه البيئة \\
\hline$\varepsilon$ & 1 & $1 \leqslant .0 V$ & .70 & 1.90 & $\varepsilon . \leqslant 7$ & $r .01$ & $\varepsilon$ & الإنتاج الحيواني \\
\hline 0 &.$\Delta V$ & IY.VE & 1.41 & r.A. & $\leq . \wedge V$ & 1.94 & $1 . \wedge r$ & الإنتاج الداجنى \\
\hline & IT.YA & 111.97 & ro.Ir & TY.VE & rV.rT & $\varepsilon \cdot r \varepsilon$ & $\leqslant 0.74$ & الإجمالي \\
\hline & & & 0 & $\varepsilon$ & $r$ & r & 1 & الترنيب \\
\hline & & & 11 & IV & $1 \leq$ & 17 & 10 & مجموع الموضو عات خلال العام \\
\hline
\end{tabular}

بلغت عدد الصفحات المشغولة بالأشكال المعنية بمجال الدراسة

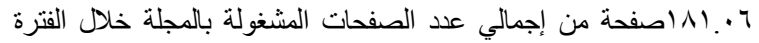

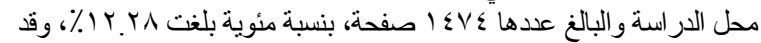

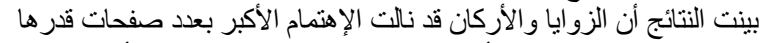
TV.Or

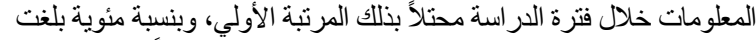

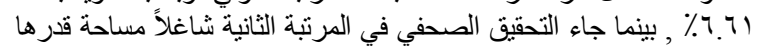

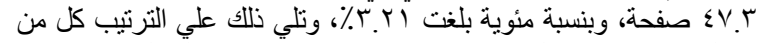

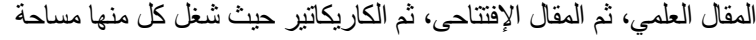

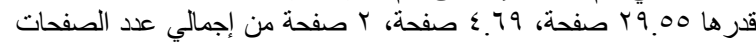

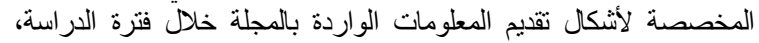

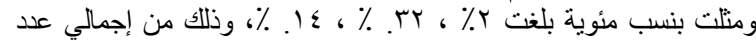

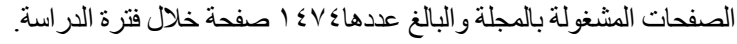

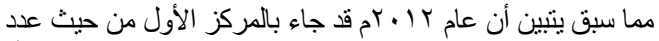

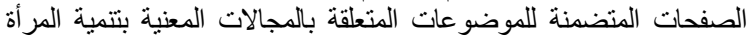

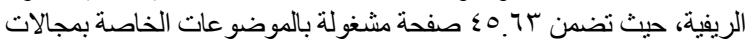

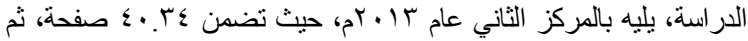

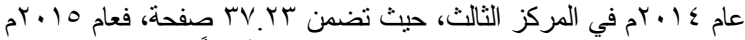

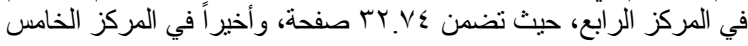

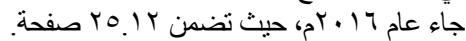

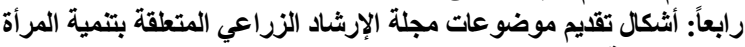

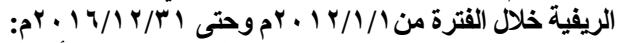

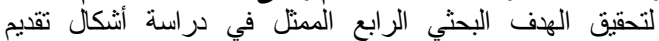

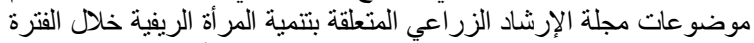

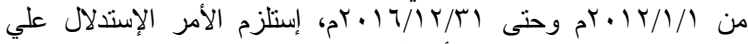

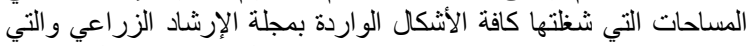

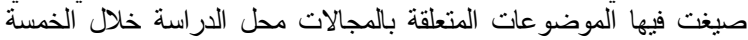
أعو ام محل الدراسة، (جدول : ؟). 
J. Agric. Econom. and Social Sci., Mansoura Univ., Vol. 9(11), November, 2018

جدول ؛. المساحة وعدد الصفحات والنسب المئوية التي شظتها أثكال تقديم الموضوعات الواردة بمجلة الإرشاد الزراعي المتطقة بتمية المرأة الريفية خلا

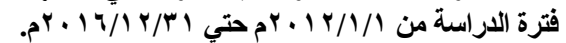

\begin{tabular}{|c|c|c|c|c|c|c|c|c|}
\hline \multirow{3}{*}{ الترتيب } & \multirow{3}{*}{$* \%$} & \multirow{3}{*}{ الإجمالي } & \multicolumn{5}{|c|}{ عدد الصفحات خلال الأعوام } & \multirow{3}{*}{ الأشكال } \\
\hline & & & $P^{Y+17}$ & pr.10 & $p^{r+1 \varepsilon}$ & pror & pror & \\
\hline & & & عدد صفحات & عدد صفحات & علد صفحات & عدد صفحات & عدد صفحات & \\
\hline$\varepsilon$ & rr & 8.79 & - & $r$ & $1 . \leqslant \wedge$ & - & 1.41 & المقال الإفتتاحى \\
\hline r & r & $r 9.00$ & .9r & $0.0 r$ & V.rT & $v . v r$ & 1. $) \leqslant$ & المقال العلمي \\
\hline r & $r . r)$ & $\varepsilon \vee . r$. & $1 . .01$ & 7.11 & 7.10 & $9 . \wedge 7$ & $1 \leqslant . \Lambda_{\Lambda}$ & التحقيق \\
\hline 1 & 7.71 & 9Y.or & 11.71 & 19.9 & rT.IV & rr.vo & r.... & الزواياو الأركان \\
\hline \multirow[t]{2}{*}{0} & $. i \leq$ & $\dot{r}$ & r & - & - & - & - & كاريكاتير \\
\hline & TY.YA & 111.97 & YO. IT & $\overline{V \varepsilon . Y Y}$ & TV.YT & 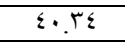 & $\$ 0.7 \pi$ & الإجمالي \\
\hline
\end{tabular}

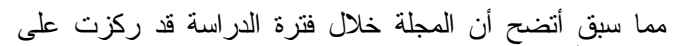

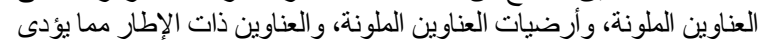

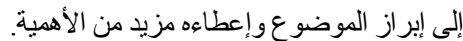

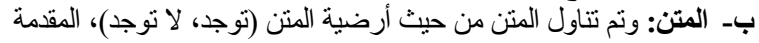

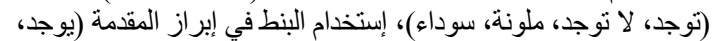

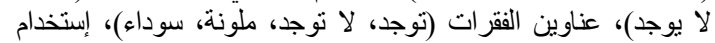

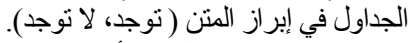

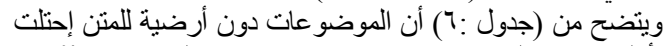

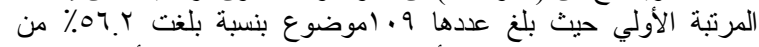

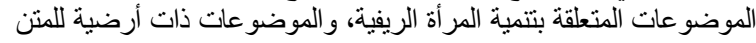

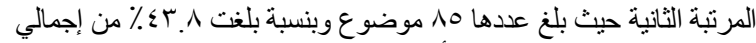
الموضو عات المتعلقة بتتمية المر أة الريفية.

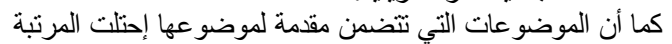

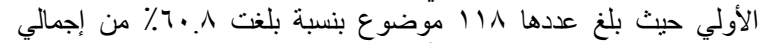

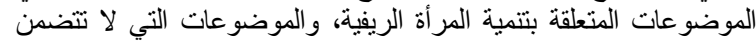

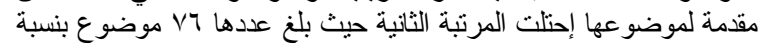

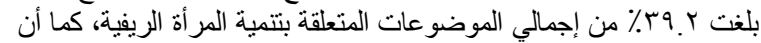

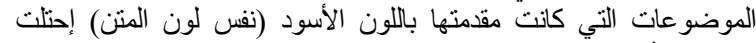

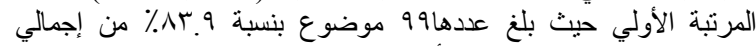

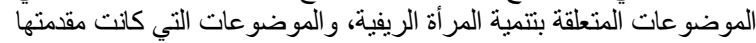

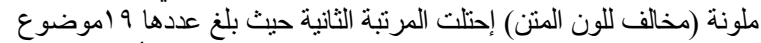

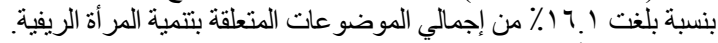

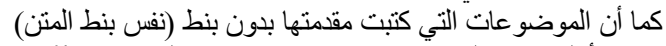

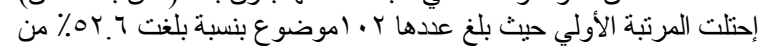

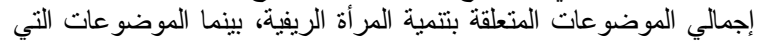

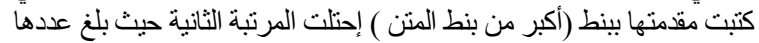

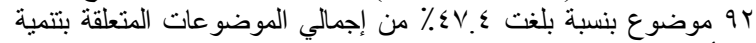

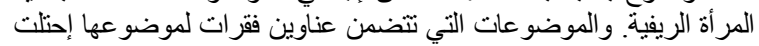

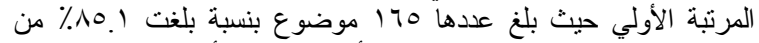

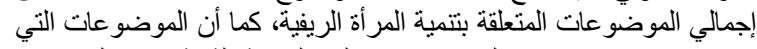

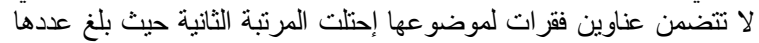

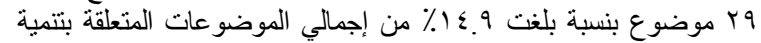

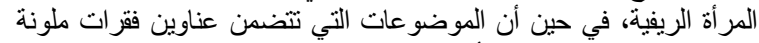

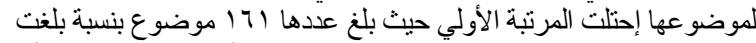

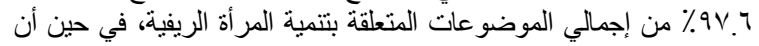

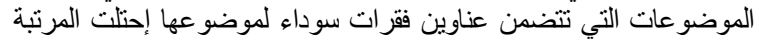

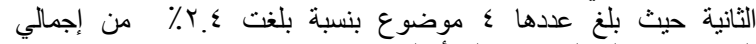
الموضو عات المتعلقة بتتمية المر أة الريفية.

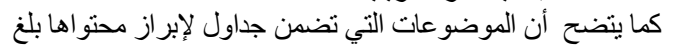

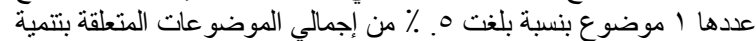
مما سبق أنضح أن المجلة خلال فترة الدراسة لم تركز بالقدر الكافي

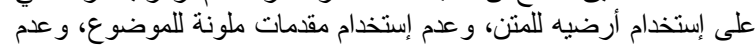

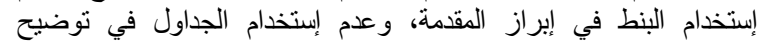
الموضوع، فكلاهما يؤدى إلى إيراز الموضوع، وجذب إنتباه التقارئ.

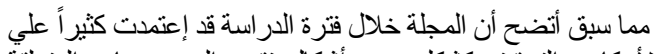

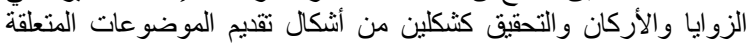

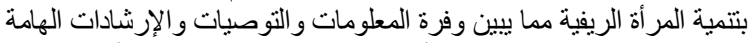

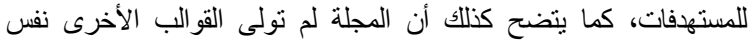

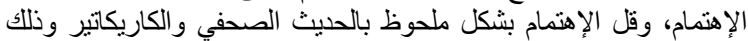
رغم أهمية هذه الأشكال.

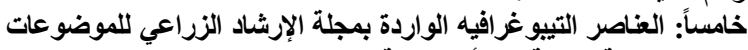

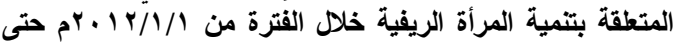

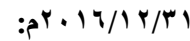

للوقوف على مدى إستخدام العناصر التييوغر افيه الواردة بمجلة التئلة الإرشاد الزر اعي للموضو عات المتعلقة بتتمية المر أة الريفية تم تقسيم العناصر التراري

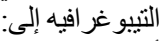

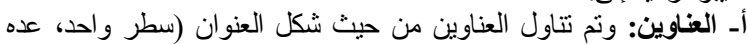

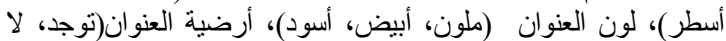

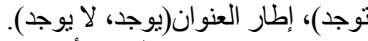

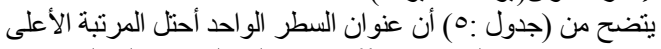

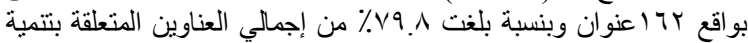

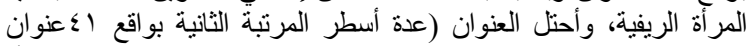

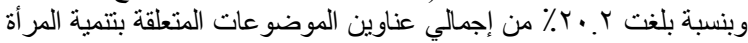

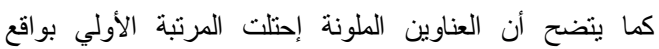

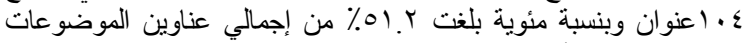

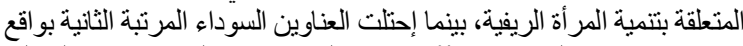

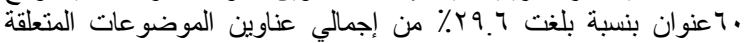

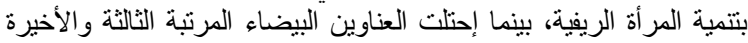

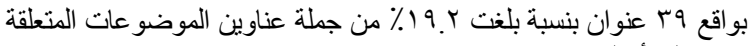
بتنمية المر أة الريفية.

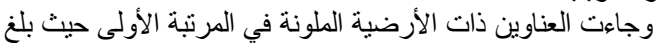

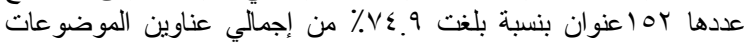

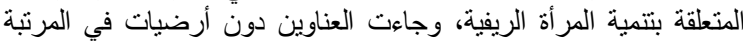

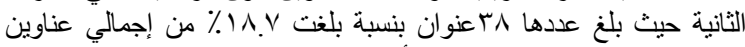

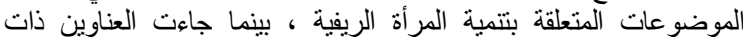

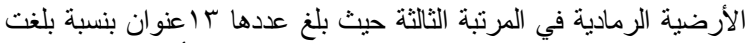

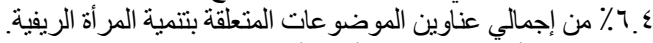

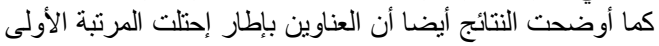

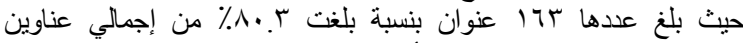

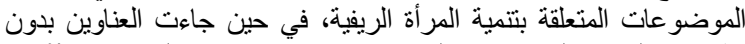

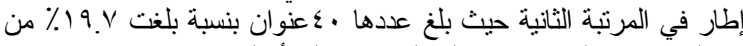
إجمالي عناوين الموضو عات المتعلة التعة بتتمية المر أة الريفية.

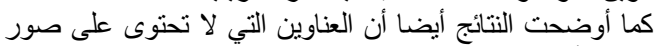

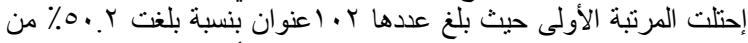

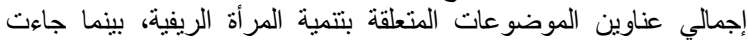

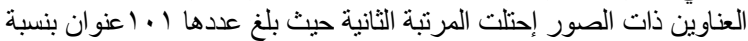
بلغت ^.؟ ؟ ٪ من إجمالي عناوين الموضو عات المتعلقة بتنمية المر أة الريفية. 
Ahmed M. A. et al.

جدول ه. شكل ولون وأرضية وإطار العناوين والنسب المئوية الواردة بمجلة الإرشاد الزراعي للموضوعات المتعقة بتنمية المرأة الريفية خلال فترة الدراسة

\begin{tabular}{|c|c|c|c|c|c|c|c|c|c|}
\hline \multirow{3}{*}{$\%$} & \multirow{3}{*}{ الإجمالي } & & & & & \multicolumn{4}{|c|}{ 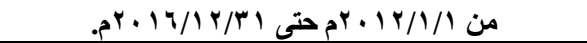 } \\
\hline & & 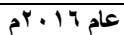 & 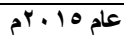 & 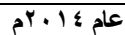 & 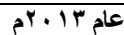 & 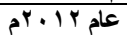 & \multirow{2}{*}{\multicolumn{3}{|c|}{ لمناصر التييوغر افيه (العناوين) }} \\
\hline & & العدد & العدد & العذد & العدد & العدد & & & \\
\hline$\vee 9 . \wedge$ & ITY & 11 & $r$. & דו & rq & rq & العدد & سطر واحد & : نيكل \\
\hline$r \cdot r$ & «1 & $\wedge$ & 0 & 0 & 11 & Ir & العدد & عدة أسطر & ل لعنوان \\
\hline $1 \ldots$ & 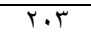 & rT & ro & « & 0. & 01 & & & لإجمالى \\
\hline 01.1 & $1 \cdot \varepsilon$ & 111 & rq & $r$. & $r$. & $r$. & العدد & ملون & \\
\hline 19.5 & rq & 1 & 1 & 1. & $\wedge$ & 9 & 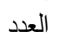 & أبيض & \\
\hline r9.7 & 7. & r & r & 11 & rr & rr & 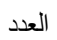 & أستود & \\
\hline $1 \cdots$ & $r \cdot r$ & rT & ro & $\S$ & 0. & 01 & & & 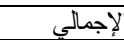 \\
\hline $1 \mathrm{~N}^{\mathrm{V}} \mathrm{V}$ & rर & v & $\varepsilon$ & 7 & $\Lambda$ & $\pi$ & العدد & لاتوجد & \\
\hline$v \leqslant .9$ & lor & 19 & r & ro & ro & rr & 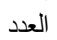 & ملونة & \\
\hline $7 . \varepsilon$ & ir & - & - & - & $v$ & 7 & 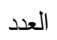 & 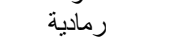 & 政 \\
\hline $1 \cdots$ & $r \cdot r$ & rT & ro & \&) & 0. & 01 & & & 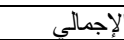 \\
\hline$\Lambda \cdot{ }^{\prime} r$ & $17 \pi$ & 10 & rq & ro & $\leqslant r$ & $\leqslant Y$ & العدد العد & يوجد & طار \\
\hline $19 . \mathrm{V}$ & $\varepsilon$. & 11 & 1 & 1 & $\wedge$ & 9 & العدد & لا بوجد & ل لعنوان \\
\hline $1 \ldots$ & r.r & rt & ro & « & o. & 01 & & & لإجمالي \\
\hline$\sum 9.1$ & 1.1 & 11 & IV & YI & $r$. & ro & العدد & عنوان به صور & لصورة في \\
\hline $0 . r$ & $1 . r$ & $\wedge$ & 11 & $r$. & $r$. & rT & العدد & عنوان بلا صور & لعنوان \\
\hline $1 \cdots$ & $T \cdot T$ & rq & ro & «) & 0. & 01 & & & لإجمالي \\
\hline
\end{tabular}

جذول \.العناصر التيوغرافيه للمتن والنسب المئوية الواردة بمجلة الإرشاد الزراعي للموضوعات المتعقة بتنمية المرأة الريفية خلال فترة الاراسة من اهن

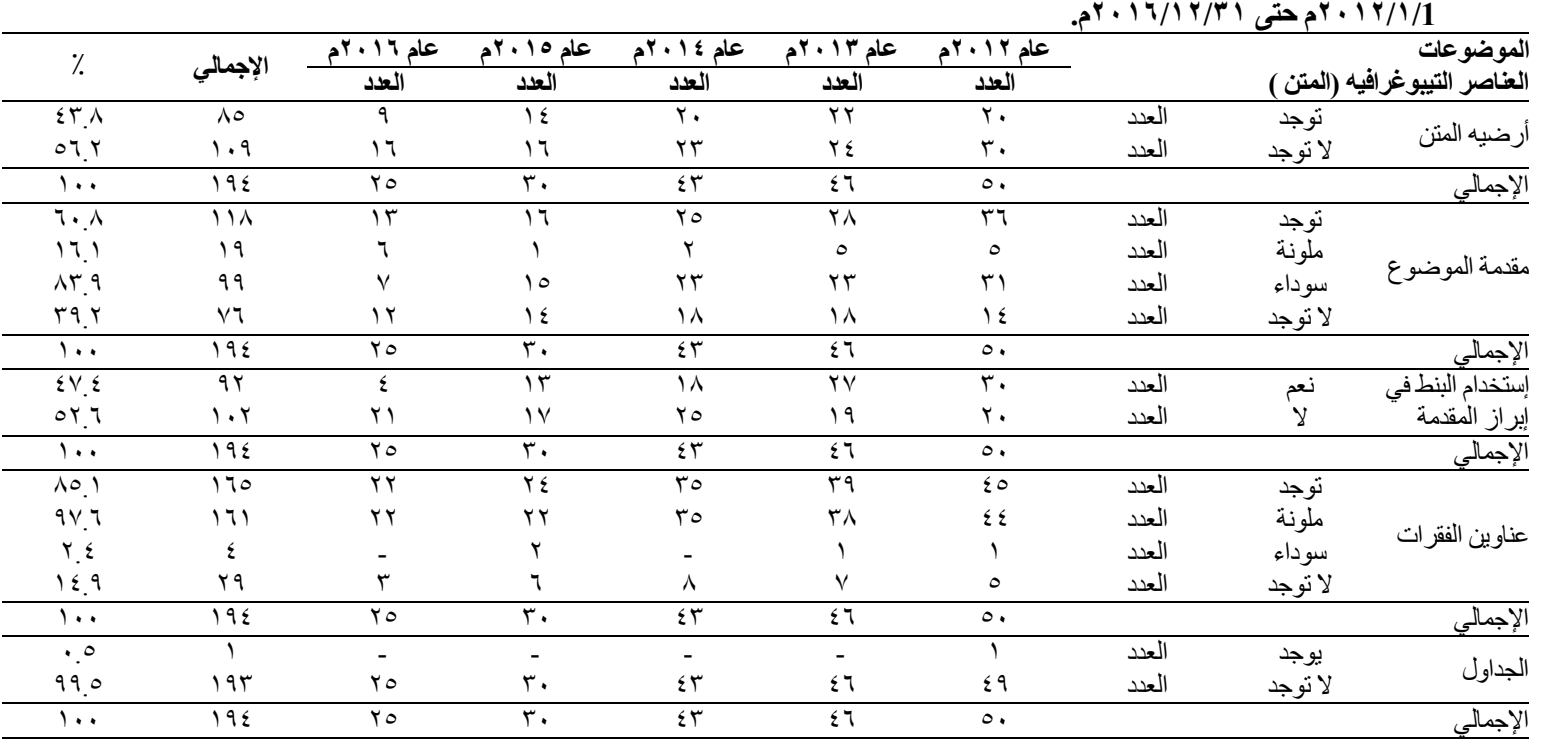

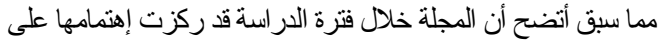

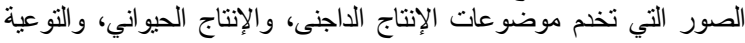

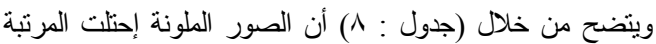

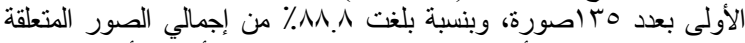

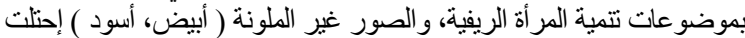

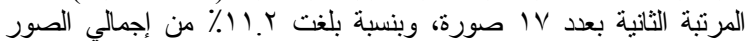
المتعلقة بموضو عات تتمية المر أة الريفية.

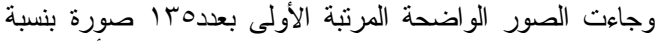

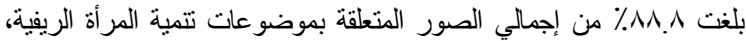

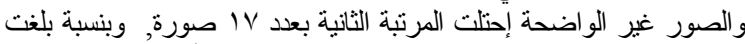

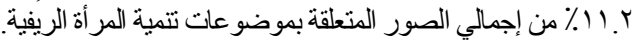

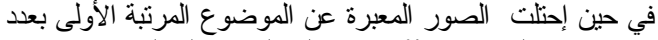

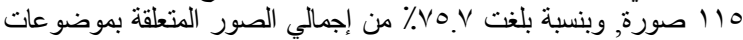

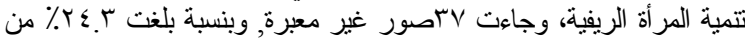

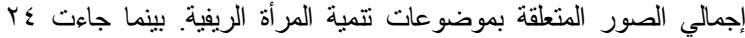

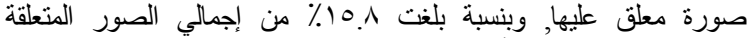

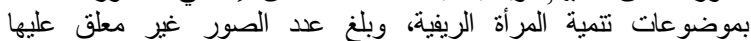

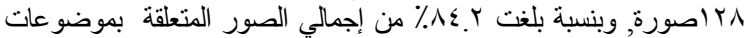

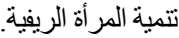

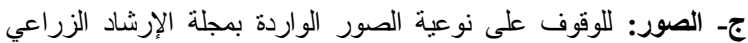

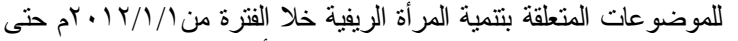

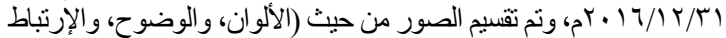

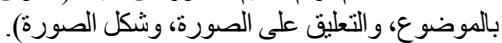

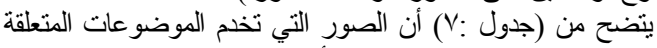

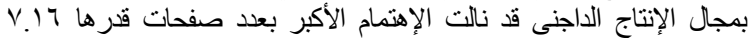

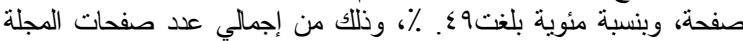

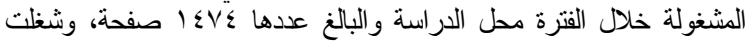

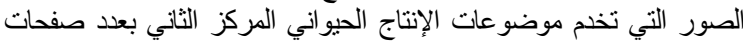

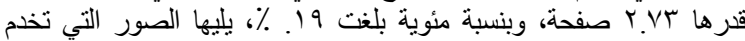

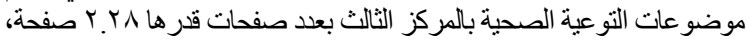

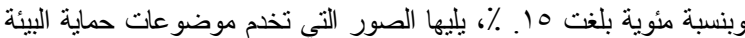

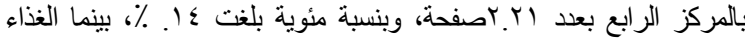

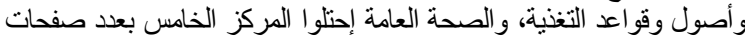

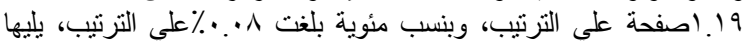

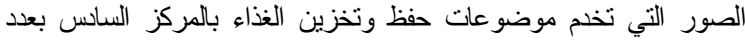

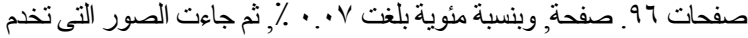

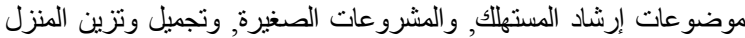

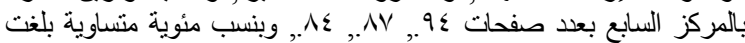

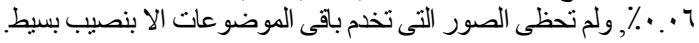




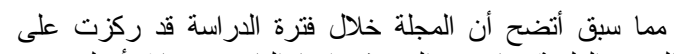

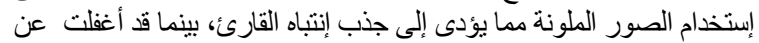

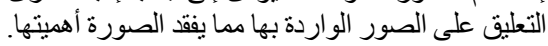

أما بالنسبة لثكل الصورة فأخذت 91 الصورة الثكل المربع بنسبة

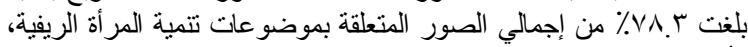

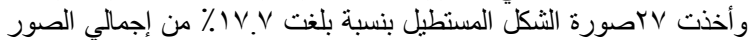

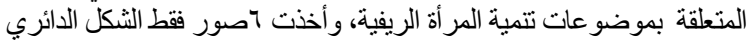

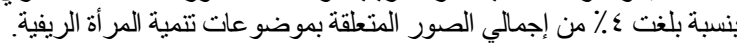

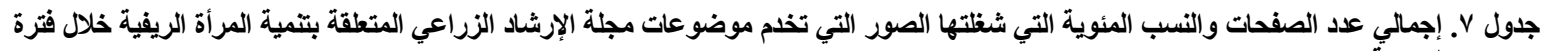

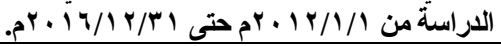

\begin{tabular}{|c|c|c|c|c|c|c|c|c|}
\hline \multirow{3}{*}{ الترتيب } & \multirow{3}{*}{$* \%$} & \multirow{3}{*}{ الإجمالي } & \multicolumn{5}{|c|}{ علد الصفحات خلال الأعوام } & \multirow{3}{*}{ الصور } \\
\hline & & & Pr. $^{r}$ & $\cos ^{r} \cdot 10$ & pr. Is & prolr & pr+1r & \\
\hline & & & العدد ال - العد & 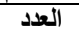 & العلد & 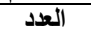 & 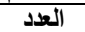 & \\
\hline- & - & - & - & - & - & - & - & الثقافة الدينية \\
\hline - & - & - & - & - & - & - & - & الثقافة العامة \\
\hline - & - & - & - & - & - & - & - & الثقافة السياسية \\
\hline$r$ & .10 & r. Y^ & (r) & . $\leqslant r$ &.$\leqslant 9$ & $1 . r$ & . $1 \leqslant$ & التو عية الصحية \\
\hline 。 & $\therefore \wedge$ & 1.19 & - & $r q$ & - & דז'. & $.0 \leqslant$ & الصحة العامة" \\
\hline 1. & $.1 \mathrm{H}$ & 11 & - & - & - & 11 & - & الأمومة والطفولة \\
\hline v & $\because 4$ & Av & - & . $\leqslant r$ & (r) & 11 & . 14 & المشرو عات الصغيرة \\
\hline 11 & $\because \cdots r$ & $\because \cdot r$ & - & $\therefore r$ & - & - & - & النظافة \\
\hline$\varepsilon$ & $.1 \leqslant$ & $r . r)$ & 1 & 1 & - & (I) & - & حمايه البيئة \\
\hline v & $\because .7$ &.$\wedge \varepsilon$ & $\because v$ & .19 & rt & 11 & 11 & تجميل وتزين المنزل \\
\hline 9 & $\because r$ & זיז. & - & - & - & זיז. & - & ترشيد الإستهلاك \\
\hline $\mathrm{v}$ & $\because 9$ & $.9 \leqslant$ & ir & 11 & דצ & $1 \leqslant$ & ו & إرشاد المُنهلك \\
\hline r & .19 & r.vr & ro & 11 & V & $\leqslant V$ & 1 & الإنتاج الحيو انى \\
\hline 1 & .99 & v.17 & 1.79 & . & 1.94 & 1.95 & 1.10 & الإنتاج الداجنى \\
\hline$\wedge$ & $\because r$ & rq & iv & - & - & r & - & التُعريف بقائدات الر أي \\
\hline$\wedge$ & $\because \cdot r$ &.$\leqslant 9$ & - & - & 11 & $r$. & 11 & طهى و إعداد الطعام \\
\hline 7 & $\because \cdot V$ & .97 & r & $.1 \leqslant$ & - & $\because 99$ & .9 & حفظ وتخزين الغذاء \\
\hline \multirow[t]{4}{*}{ 。 } & $\because \wedge$ & 1.19 & 11 & - & . & IV &.$v$ & الغذاء وأصول وقو اعد التغذية \\
\hline & $1 . \leqslant V$ & YI.V9 & $\varepsilon .1 T$ & T.Y & $\varepsilon .1$ & 0.71 & $\varepsilon . V \mu$ & الإجمالي \\
\hline & & & $r$ & 0 & $\varepsilon$ & 1 & r & التزرتبب \\
\hline & & & 9 & 1. & $\Lambda$ & $1 \varepsilon$ & T. & مجموع الصور خلال العام \\
\hline
\end{tabular}

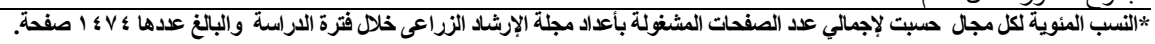

جدول ^. العناصر التيبوغرافيه للصور والنسب المئوية التولية الواردة بمجلة الإرشاد الزراعي للموضوعات المتعلقة بتنمية المرأة الريفية خلال فترة الدراسة من

\begin{tabular}{|c|c|c|c|c|c|c|c|c|c|}
\hline$\%$ & الإجمالي & عام 17 1". & 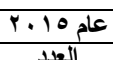 & 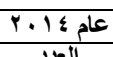 & 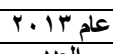 & عام Y I" Y & $1 / 1$ & \multirow{2}{*}{\multicolumn{2}{|c|}{ العناصر التيبوغرافيه ( الصورة) }} \\
\hline$\wedge \wedge \wedge$ & 1 To & 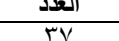 & العدد & العدد & العدد & العدد & & & \\
\hline $11 r$ & IV & rit & 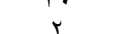 & 19 & rr & & العدد & ملأ ملونه & له ن الصورة \\
\hline & $10 r$ & $\frac{-}{\mu V}$ & $\frac{1}{4 y}$ & r & $\Lambda$ & 0 & العدد & ابيض و اسود & \\
\hline $1 \ldots$ & & rV & rT & T1 & $r$. & TY & & & الإجمالي \\
\hline$\Lambda \wedge . \wedge$ & $1 \% 0$ & TV & rY & rq & T) & 17 & العدد & وواضحة & \\
\hline $11 . r$ & IV & - & - & $r$ & 9 & 7 & العدد & غير و اضحة & ورن \\
\hline $1 \ldots$ & 104 & TV & Tr & 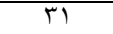 & $r$. & YY & & & الإجمالي \\
\hline VO. V & 110 & एะ & TV & Tr & 17 & 10 & العدد & معبرة & إرتباط آلصورة \\
\hline$r \leqslant . r$ & rV & $r$ & 。 & $\wedge$ & $1 \leqslant$ & v & العدد & غبر معبرة & بالموضوع \\
\hline $1 \ldots$ & 104 & TV & Tr & Tा & $r$. & YY & & & الإجمالي \\
\hline 10.1 & TE & Tr & r & $r$ & $\varepsilon$ & $\Gamma$ & العدد & معلق عليها & التنعليق على \\
\hline$\Lambda \leqslant . r$ & KN & ro & r. & rA & ז & 19 & العدد & غير معلق & الصورة \\
\hline $1 \ldots$ & 104 & TV & rY & ri & $r$. & YY & & & الإجمالي \\
\hline$V \wedge . r^{r}$ & 119 & TV & To & TV & Tr & IV & العدد & مربع & \\
\hline IV.V & rV & 9 & $r$ & $\varepsilon$ & V & $\varepsilon$ & العد & مستطيل & الصصرة \\
\hline$\varepsilon$ & 7 & 1 & $\varepsilon$ & - & - & 1 & العدد & دائري & الصورة \\
\hline $1 \ldots$ & 104 & TV & rY & TI & $r$. & YY & & & الإجمالي \\
\hline
\end{tabular}

جدول 9. مصدر مادة الإتصال والنسب المئوية الواردة بمجلة الإرشاد المبرة

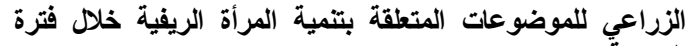

\begin{tabular}{|c|c|c|c|c|c|c|c|}
\hline \multirow{2}{*}{$* \%$} & \multirow{2}{*}{ الإجمالي } & \multicolumn{5}{|c|}{ عدد الموضوعات } & \multirow{2}{*}{ مادة } \\
\hline & & pr.17 & Sr.10 & pr. l & $p^{r+1 r}$ & $p^{r+1 r}$ & \\
\hline $.7 \mathrm{~V}$ & 1. & $r$ & $\varepsilon$ & 1 & r & - & \\
\hline$\varepsilon . \wedge$ & VY & v & $\wedge$ & ir & 19 & r & بيل \\
\hline$\Lambda . M \Lambda$ & IKr & IV & 19 & YV & rT & TV & نيين \\
\hline$\overline{I T . \wedge T}$ & $r \cdot \varepsilon$ & $T V$ & Tा & $\varepsilon$ & or & or & مالر \\
\hline
\end{tabular}

"النسب المئوية حسبت لإجمالي علد الصفحات المشغولة في مجلة الإرشاد الزراعى خلال فترة

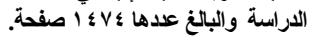

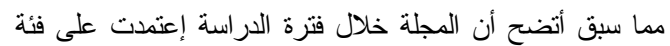

المهنيين كمصدر للمعلومات الواردة بها والمتعلقة بتتمية المر أة الريفية.

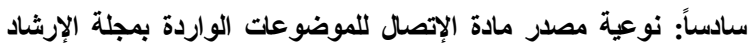

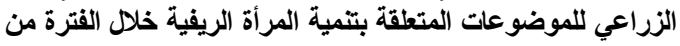

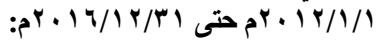

للوقوف على نوعية مصدر مادة الإتصال الو الواردة بمجلة الإرشاد

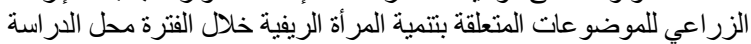

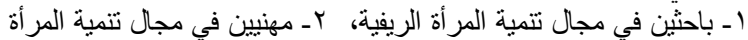

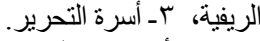

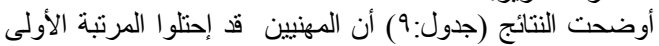

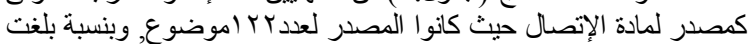

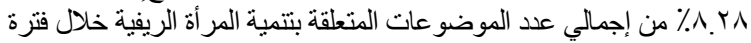

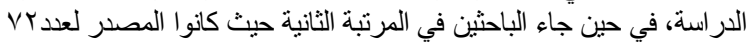

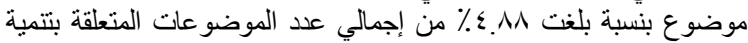
المرأة الريفية، بينما جاءت أسرة التحرير في المبر المرتبة الثالثة والأخيرة حيث

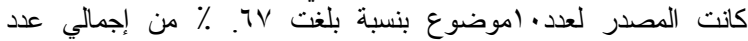
الموضو عات المتعلقة بتتمية المر أمة الريفية. 


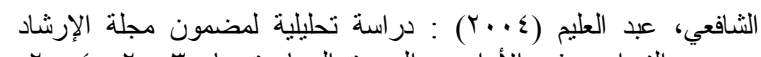

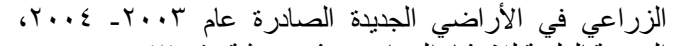

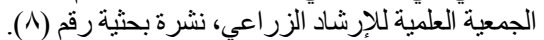

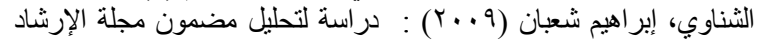

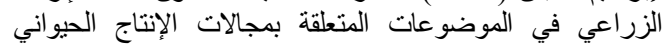

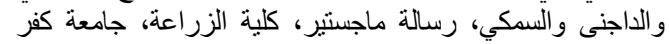

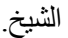

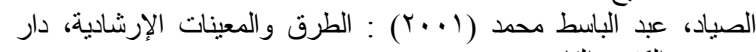
الكتب، القاهرة.

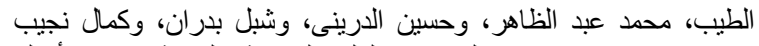

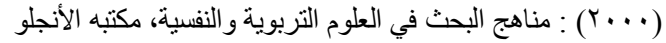

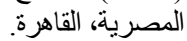

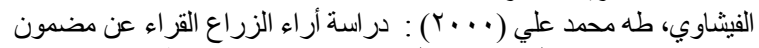

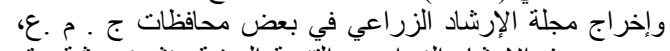

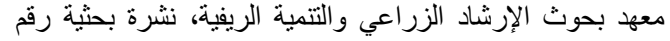

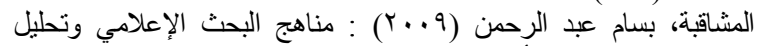
الخطاب، دار أسامة للنشر و التوزيع، عمان.

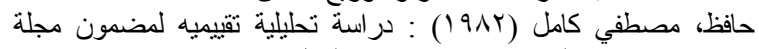

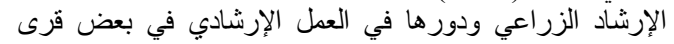

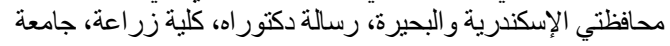
الإسكندرية.

حسن، سمير محمد (1997) ) : الإعلام والإتصال الجماهيرية والر أي العام،

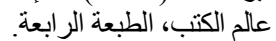

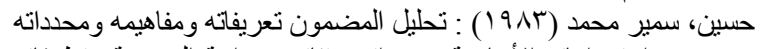

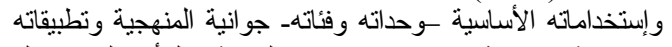

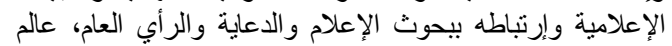

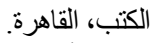

رشتي، جيهان أحمد (9V9) :مذكرات في تحليل المضمون، معهر التليفزيون، القاهرة.

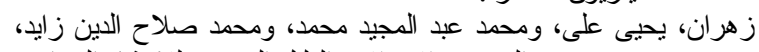

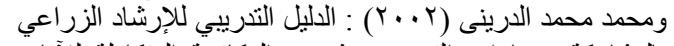

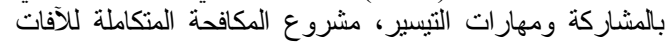
بمحافظة الفيوم، وزارة الزراعة التير، واستصلاح الأراضي، جمهورية مصر العربية.

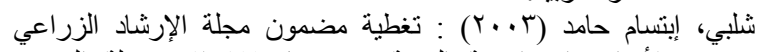

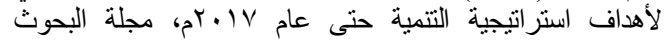

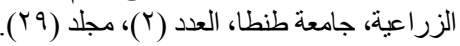

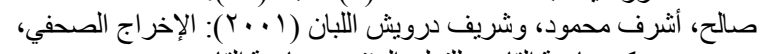

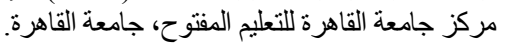

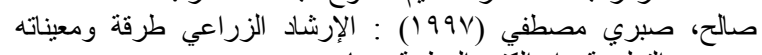
التعليمية، دار الكتب الوطنية، بنغازي.

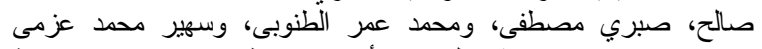

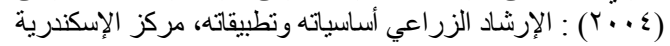

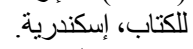

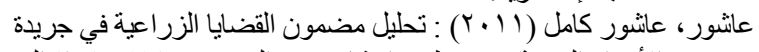

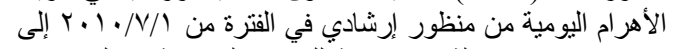

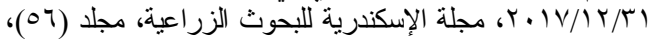

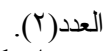

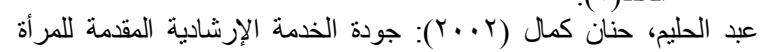

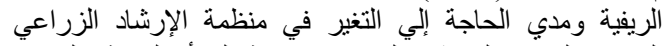

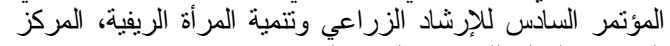

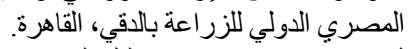

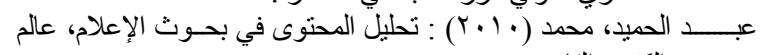

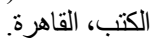

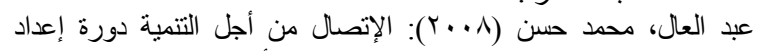

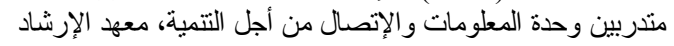
الزر اعي و التنمية الريفية، بالقاهرة.

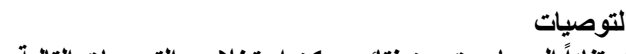

إستثاداً إلى ما سبق من نتائج يمكن إستخلاص التوصيات التالية:

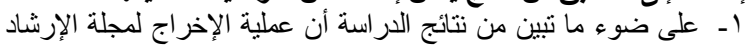

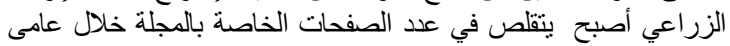

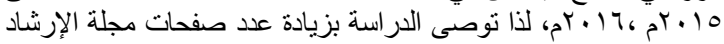

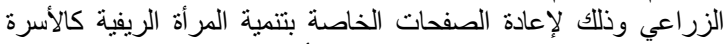

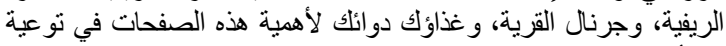
المر أة الريفية وتنميتها.

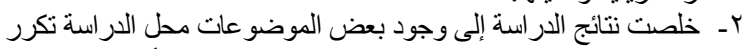

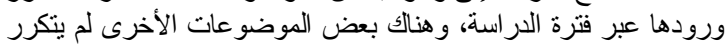

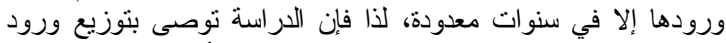

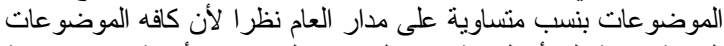

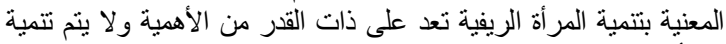

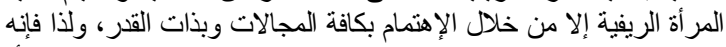

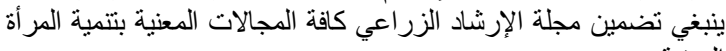
الريفية. r- تبين من نتائج الدراسة أن إجمالي عدد الصفحات المعنية بتتمية المرأة أرنات

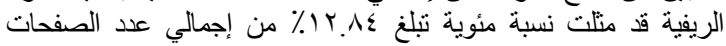

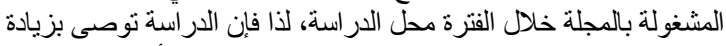

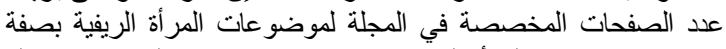

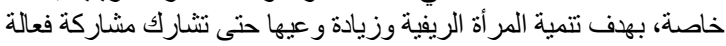
في منطلبات حياتها اليومية.

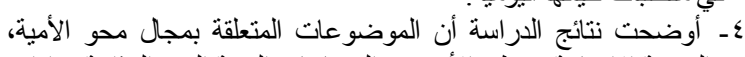

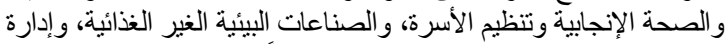

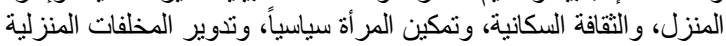

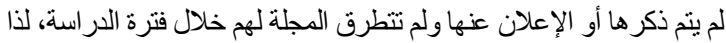

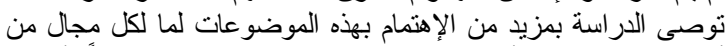

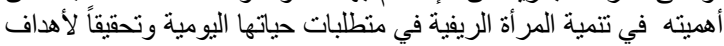

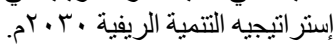

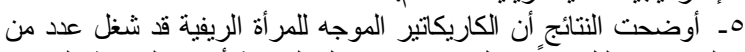

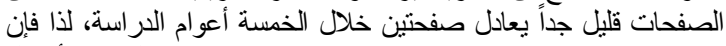

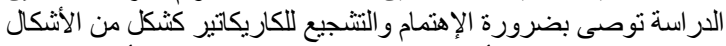

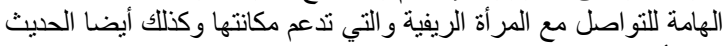

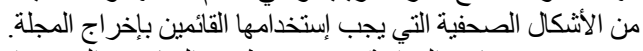

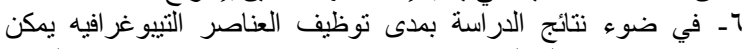

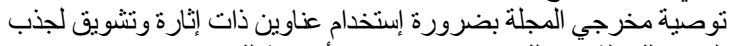

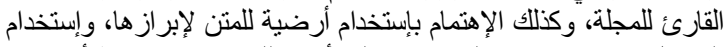

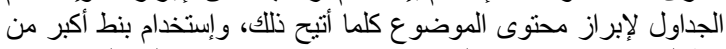

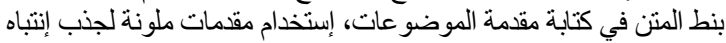

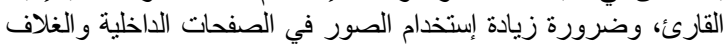

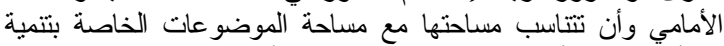

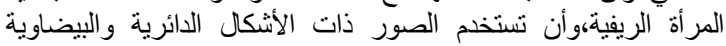

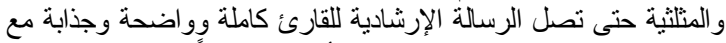

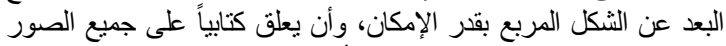

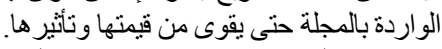

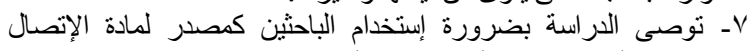
و إستخدام المهنيين فى عملية الإخر اج الصحفى.

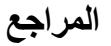

أحمد، غريب محمد سيد (1911) :علم الإجتماع الريفي، دار المعرفة الجامعية، الإسكندرية.

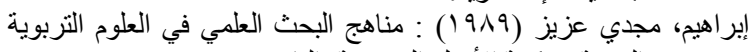

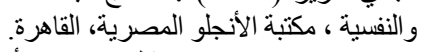

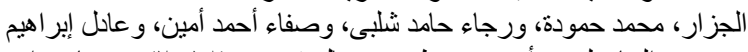

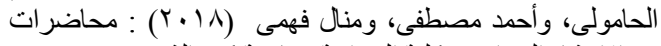
في الإرشاد الزراعي، كلية الزراعة واعة، جامعة كفر الثيخ.

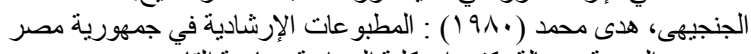

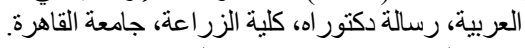

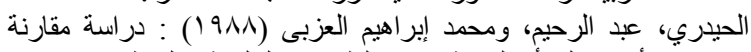

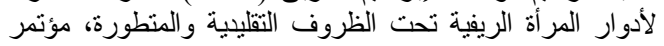

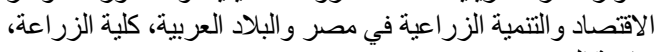

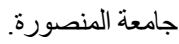




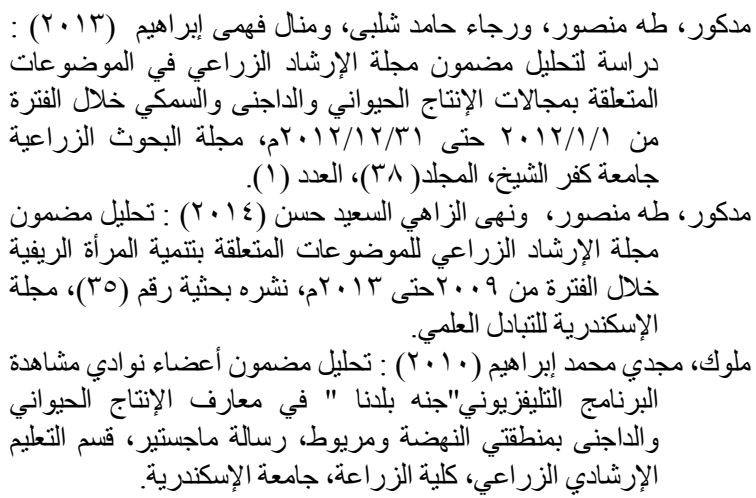

Swanson, B.E (1990): Agricuture extension, Areference manual, second edition, F.A.O of the United Nations Ron

Maunder, H. (1973): Agricultural Extension, A Reference Manual, Second Edition, FAO, Rome

Sanders, H. and Others (Eds) (1966): The Co- operative Extension Service, Printice, Hall, Inc, New York

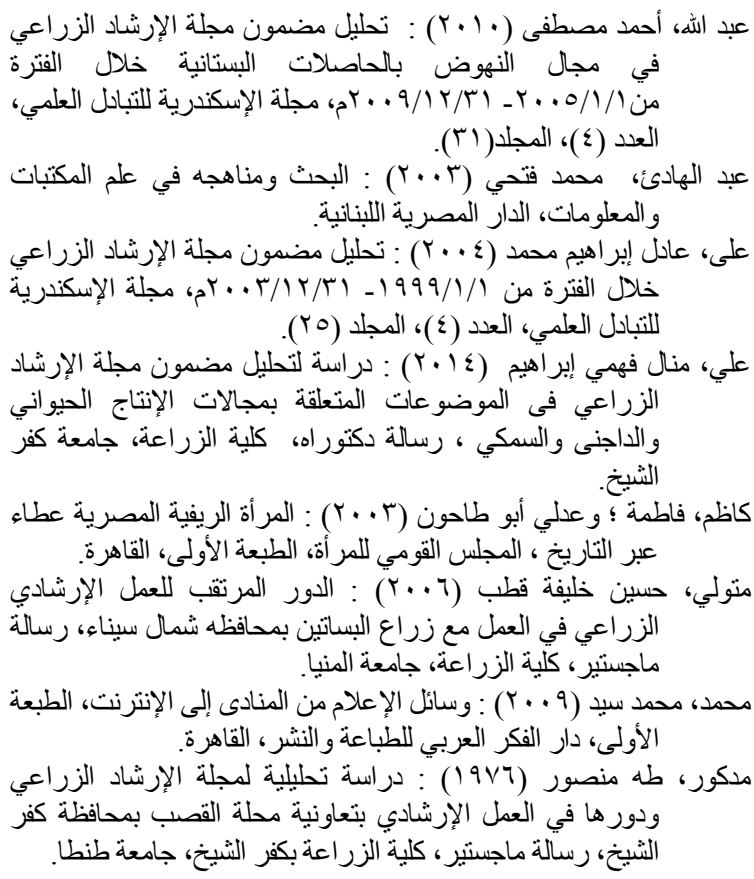

A Study to Analyse the Content of Agricultural Extension Magazine about Rural Women Development Subjects during the Period from 1/1/2012 to 31/12/2016. Ahmed M.A ${ }^{1}$; A. M. El- Gohary ${ }^{1}$; E. F. El- Zahar ${ }^{2}$ and Maha M. M. Fera ${ }^{1}$ ${ }^{1}$ Tanta University - Faculty of Agriculture - Agricultural Economics Department. ${ }^{2}$ Agricultural Extension and Rural Development Research.

\begin{abstract}
The main aim of this study is to analyze the content of agricultural extension magazine about rural women development subjects during the period from1/1/ 2012 to 31/12/2016, through the identification of the magazines included in the agricultural extension magazine and the amount of space available for these subjects during the study period as well as the nature of the content, and content of the issues mentioned in the magazine on the field of rural women's development, as well as the extent to which the cover the topics, the forms of their presention, the extent of the use of the typographic elements to serve them, rural during the study period. The study reached a set of results summarized as follows: 1-The results indicated that the topics mentioned in the Agricultural Extension magazinl during the study period were in seven fields: plant production, animal, poultry and fish production, protection of the rural environment, Carrie subjects, rural women, economic insects, and insect pests. the results showed that topics related to the field of production plant has occupied the first place among the areas where by $52.87 \%$, has been occupied topics related to animal production, poultry and fish second where by $16.36 \%$. has been occupied topics related to rural women development varied in third place where she by $13.76 \%$, while the occupied areas of protection of the rural environment, and insects pests, Carrie subjects, insects of economic ranked fourth, fifth, sixth, seventh rates of $7.79 \%, 4.83 \%, 3.44 \%, 0.95 \%$ respectively. 2- Concerning identifying the nature of the magazine content related to the development of rural women during the period of the study, The results indicated that the topics related to the development of rural women during the study period were in the following areas: Subjects related to the field of religious culture ranked first with a percentage of $2.35 \%$, Followed by health awarenes by $1.70 \%$, Followed by public health by $1.6 \%$, Then animal production topics by $1 \%$, The topics of poultry production by $.87 \%$, Followed by topics related to consumer guidance and small Projects by $.72 \%, .63 \%$, Followed by topics of Food and the Principles and Rules of Nutrition, Conservation and Storage of Food by $.60 \%$, and Field topics Clearness of the home, Cooking and Food Preparation, Motherhood and Childhood, General Culture, Identification of the Opinion Leaders, Protection of the Environment, Cleanness, Political Culture by $.48 \%, .40 \%, .31 \%, .28 \%, .18 \%, .17 \%, .18 \%, 0.07 \%$ respectively. 3With regard to the magazine presentation five forms Article Scientific ' Editorial، Caricature، Angles and Corners، Investigation، the results showed that the Angles and Corners has received the most attention on the part of the magazine where by $6.61 \%$ of the total number of pages devoted to the forms provide information occupied so the first place، while the Investigation into the second Concern an area of 47.3 pages by $3.21 \%$, followed by, respectivel,each Article Scientific and then the Editorial, Caricature where by $2 \%, .32 \%, .14 \%$, of the total number of pages devoted to the forms provide information contained in the magazine.
\end{abstract}

